\title{
DISCLAIMER
}

This report was prepared as an account of work sponsored by an agency of the United States Government. Neither the United States Government nor any agency thercof, nor any of thutir employees, makes any warranty, express or implied, or assurtes any legal liability ot tesponsibility for the accuracy, completeness, of usefulness of any information, apparatus, product, or process disclosed, or represents that its use would nat infringe privately owned rights. Reference herein to any specilic commercial product, process, or service by trade name, trademark, manufacturer, or otherwise dnes not nesessarily constitule or imply its endorsement, recom. mendation, or favoring by the United States Government of any agency thereot. The views and opinions of authors expressed herein do not necessarily state or reflect those of the United States Goverament or any agency thereor.

\section{Langmuir Probe Measurements in the TEXTOR Tokamak During ALT-I Pump Limiter Experiments}

UCLA/PPG --945

DE86 015878

D.M. Goebel, G.A. Campbell, R.W. Conn, W.K. Leung

K.H. Dippel, K.H. Finken, G.J. Thomas, A.E. Pontau

April 1986

UCLA-PPG-945

This paper has been submitted to Plasma Physics and Controlled Fusion. Please do not use any portion of this paper without permission from the authors.

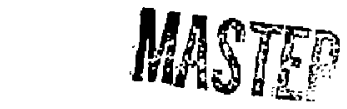




\title{
Langmuir Probe Measurements in the TEXTOR Tokamak During ALT.I Pump Limiter Experiments
}

\author{
D.M. Goebel, G.A. Campbell, R.W. Conn, W.K. Leung \\ University of Califormia, Los Angeles, Los Angeles, CA 90024 , U.S.A. \\ K.H. Dippel, K.H. Finken \\ Institute of Plasma Physics, Association Euratom-KFA Juelich, F.R.G. \\ G.J. Thomas, A.E. Pontau \\ Sandia National Laboratories, Livermore. CA 94.550, U.S.A.
}

\begin{abstract}
Langmuir probes have been used to characterize the edge plasma of the TEXTOR tokamak and measure the parameters of the plasma incident on the ALT-I pump limiter during ohmic and ICRH heating. Probes mounted directly on the ALT limiter, and a scanning probe located $90^{\circ}$ toroidally from the limiter, provide data for the evaluation of pump limiter performance and its effect on the edge plasina. The edge plasma is characterized by density and flux e-folding lengths of about $1.8 \mathrm{~cm}$ when ALT is the main limiter. These scrape-off lengths do not vary significantly as $\mathrm{ALT}$ is moved between the normal $42-46 \mathrm{~cm}$ minor radii, but increase to over $2.2 \mathrm{~cm}$ when ALT is inserted to $40 \mathrm{~cm}$. The flux to probes at a fixed position in the limiter shadow varies by less than $25 \%$ for core density changes of a factor of five. This suggests that the giobal particle confinement time, $\tau_{p}$, scales as the core density. Estimates from the probes indicate that $\tau_{p}$ is on the order of the energy confinement time, $\tau_{E}$. The edge electron temperature, $T_{e}$, typically decreases by a factor of two when the core density is raised from 1 to $4 \times 10^{13} \mathrm{~cm}^{-3}$. The $T_{e}$ profile is essentiafly flat in the limiter shadow, with values of $10-25 \mathrm{eV}$ depending on the core plasma density and ICRH power. ICRH heatung increases the edge electron temperature and flux in proportion to the coupled power. With ALT as the primary limiter and no direct shadowing, the ion side receives 2 to 3 times the flux of the electron side during both ohmic and ICRH heating. The edge plasma is not directly modified by pump limiter operation, but changes with the core plasma density as particle removal lowers the recycling of neutrals in the boundary.
\end{abstract}




\section{INTRODUCTION}

The Advanced Limiter Test (ALT-I) ${ }^{1-3}$ is a pump limiter experiment on the TEXTOR tokamak ${ }^{4}$. The purpose of this experiment is to study the particle removal capabilities of several actively-pumped limiter modules in the long pulse-length plasma of TEXTOR. To understand the pump limiter operation and efficiency in removing particles iscident on the entrance slots of several different limiter geometries, a series of probe studies have been undertaken. The Langmuir probes are utilized to measure the scrape-off layer (SOL) plasma parameters such as density, electron temperature, parallel ion flux to the limiter entrance slot, and radial scrape-off efolding lengths of these respective parameters. Meastrements of these values are made both locally at the limiter by probes mounted on and inside the ALT module, and by a scanning probe positioned $90^{\circ}$ toroidally from $\mathrm{ALT}$.

Characterizations of the scrape-off layer plasma by probes have been made in most major tokamaks such as PLT ${ }^{5}, \mathrm{PDX}^{6}, \mathrm{ISX}_{-\mathrm{B}^{7}}, \mathrm{DITE}^{8,9}, \mathrm{ASDEX}^{10}$, Alcator-C ${ }^{11}$, and TFTR ${ }^{12,13}$. Probe data has also been used in the interpretation of results from past pump limiter experiments: the Box pump limiter on Mactotor ${ }^{14}$, the Scoop on PDX ${ }^{15}$, and the Mushroom limiters on ISXB16, for example. The ALT experiments have several features not available in these other studies. In particular, TEXTOR is capable of very high recycling from hot walls, and has a pulse length of over 3 seconds which is long compared to the gas flow time constants in the tokamak vessel. Probe data provides information on the TEXTOR SOL plasma and the total ion flux entering the limiter opening. Performance by different pump limiter geometries, and the removal efficiency during active pumping, can then be determined. Additional investigations of the SOL plasma modifications during ICRH auxiliary heating ${ }^{17}$ of up to $2 \mathrm{MW}$ have been made and will be discussed.

The TEXTOR tokamak ${ }^{4}$ has been described elsewhere. Typical conditions during ALT experimests are: $R_{0}=1.75 \mathrm{~m}, \mathrm{a}=40-48 \mathrm{~cm}, \mathrm{I}_{\mathrm{p}}=350 \mathrm{kA}, \mathrm{B}_{\mathrm{T}}=2.0 \mathrm{~T}, \mathrm{n}_{\mathrm{e}}=1-5 \times 10^{13} \mathrm{~cm}^{-3}, \mathrm{~T}_{\mathrm{e}}(0)<$ $1.2 \mathrm{keV}$, and $\mathrm{T}_{\mathrm{i}}<1 \mathrm{keV}$. The liner temperature is normally maintained between $150-300^{\circ} \mathrm{C}$, and the walls are carbonized ${ }^{18}$ prior to plasma operation. ALT $-I$ is inserted into the TEXTOR edge as 
an additional limiter, and has the ability to be moved between shots from 40 to $50 \mathrm{~cm}$ minor radius. The TEXTOR limiters are also movable, and are normally retracted to a $43 \mathrm{~cm}$ radius during the ALT program.

\section{П. EXPERIMENTAL ARRANGEMENT}

ALT has three different limiter modiles, each of which can be mounted on the common manipulator and pumping system. The "closed" pump limiter geometry, with a low conductance for neutral gas to escape to the plasma and named AI.T-VG, is shown schematically in Fig.l. The more "open" geometry, named ALT-FG2 and shown schematically in Fig.2, features twosided collection and a higher conductance for backflowing gas. The ALT-FG1 is similar in design to the ALT-FG2, having a different neutalizer plate geometry but identical probes. The views of ALT in Figs.1 and 2 show the probe locations for the two modules. ALT-VG has five fixed probes, located between the entrance into the limiter and the plasma neutralization plate. The probe mounted exterior to the throat region (called the EXALT probe), is used to measure the plasma parameters at the entrance to the limiter. The three throat probes are staggered radially in the same poloidal plane to provide rough information on the scrape-off lengths locally at ALT. The combination bolometer-Langmuir probe at the neutralizer plate has a thermoccuple attached to measure the heat flux striking the neutralizer region. The ALT-FG2 module has two probes centered in the entrance slot and facing in the ion and electron directions. The ALT-FG2 probes are of the same design as the EXALT probe.

The probe design was determined largely by the high hat flux and long pulse length requirements of being part of the primary limiter in TEXTOR. ALT is designed to handle ap to 1MTW of power for 3 seconds. Preliminary anaiysis indicated that passively coolea molybder.m probes located at the entrance slot must have a diameter of at least $4 \mathrm{~mm}$ in order remain below the temperature for thermionic electron emission during the TEXTOR pulse. The single, flat faced probes shown in Fig.3a, with a Mo shield to eliminate collection from the sides and back, were installed to measure the parallel ion flux, density, and electron temperature of the plasma flowing 
into the entrance of ALT. The fact that the probes are mounted directly on a very large limiter means that they are shadowed at the rear and receive flux from the plasma facing side. It will be shown in Section $V$ that the probes in the entrance are sufficiently close to the plasma neutralization plate in the limiter shadow to correctly measure the incident flux into the entrance slot. The probe collection area is well determined by the shield opening, and any backflowing plasma that might be generated by ionization in the throat region is collected on the shield. The shield and the entire ALT limiter float relative to the rest of TEXTOR, and act as the reference electrode ${ }^{19}$ in the probe circuit.

The scanning Langmuir probe, modified from a deposition probe 20 and located $90^{\circ}$ toroidally from the ALT position on the horizontal midplane, is shown in Fig. 3b. This probe is not positioned on the field line that intersects ALT directly, and like ALT has a very long connection length (several times around the torus when ALT is the primary limiter) to other limiters. The probe head is made of graphite, with the plasma collected by a biased Ta electrode positioned behind the aperture. The Ta electrode is thermally isolated from the structural support, and also acts as a bolometer to measure the parallel heat flux in the SOL. Measurements of the heat flux and the power scrape-off length will be reported elsewhere. ${ }^{21}$ The scanning probe floats relative to the limiters and liner in TEXTOR, and acts as a double probe of greatly unequal areas.

The probes are driven by identical sets of electronics coupled to a common data acquisition system. The probe bias is supplied by bipolar power supplies, which are driven by a linear ramp from a common programmable function generator. It is therefore a simple matter to check the linearity of the voltage sweeps with the computer and detect noise induced distortions. Voltage sweeps of $\pm 60 \mathrm{~V}$ for $2-5 \mathrm{msec}$ are typically used. Precision shunt resistors are used to detect the probe current, and high impedance voltage dividers monitor the probe bias. The probe signals are optically isolated from the Camac Crate data loggers at TEXTOR diagnostic ground. Each system was tested for $20 \mathrm{kHz}$ operation and up to $1.5 \mathrm{kV}$ isolation, with special care taken to avoid grcund loops. The bipolar power supplies current limit probe arcs, eliminating possible melting of the probe tips by arcing during the long pulse lengths. The problem of the circuit 
breakers tripping on the Kepco bipolar power supplies was eliminated by disabling a remotecontrol shut-off option that was sensitive to if noise and common-mode voltage jumps which occur during disruptions.

An example of the line averaged core plasma density from a standard discharge, and the associated ion saturation current signal from the EXALT probe, is shown in Fig.4. The probe data loggers are normally operated in the burst acquisition mode during the probe voltage sweep period to decrease the data memory requirements, resulting in the short gaps in the trace. The typical level of oscillations in the ion saturation current $(\delta \mathrm{I} / \mathrm{I})$ is $20-30 \%$. Closing the throat to ALT allows examination of the noise pickup by the throat probes, which is found to be negligible even during ICRH heating. Electron temperature data is oblained by initiating the voltage sweeps during the data acquisition periods and evaluating the current-voltage curves. Up to 300 traces from the six probes are stored and analyzed for each shot.

\section{PROBE SIGNAL ANALYSIS}

Proper analysis of the local plasma parameters in tokamak SOL plasmas from Langmuir probe I- $V$ characteristics has received considerable attention in recent years. The standard theory described by $\mathrm{Chen}^{22}$ has been widely used to evaluate the plasma density and electron temperature from the ion saturation current and voltage sweeps of single and double probes. This technique still works well in certain cases, in spite of some uncertainties due to the effects of strong magnetic fields and edge ion temperatures exceeding the electron temperature. Recent analysis by Stangeby ${ }^{23-25}$ has refined the modeling of probe characteristics for tokamak edge plasmas. Additional work by Stangeby $19,26,27$ details the effect of large probes in the SOL. plasma and provides techniques to evaluate the local plasma parameters from the probe traces. The probe interpretation described here for the large, flat probes in the shadow of ALT-I has been recently detailed by Stangeby 19 .

The current to the single probe in the portion of the current versus voltage characteristic with small electron collection is given by 


$$
I(V)=\frac{1}{2} \pi_{e} e c_{s} A-\frac{1}{4}\left(8 T_{e} / \pi m_{e}\right)^{1 / 2} n_{e} e A \exp \left[-\left(V-V V_{p}\right) / k T_{e}\right]
$$

where $c_{\$}=\left[k\left(T_{e}+T_{i}\right) / M_{i}\right]^{1 / 2}, n_{e}$ is the plasma density, $A$ is the probe collecting area, $v_{p}$ is the plasma potential, and $T_{e}$ and $T_{i}$ are the electron and ion temperatures respectively. The ion and electron temperatures have been assumed to be equal in our calculations. Stangeby's model ${ }^{23}$ accounts for the strong reduction in the electron current due to the magnetic fields by introducing an electron diffusion parameter " $r$ " in the $I(V)$ equation. This model need not be included in our case unless fits to the large electron current region of the probe characteristic are needed 23 . Equation 1 is used in our analysis to determine density and electron temperature by a least squares fitting routine over the portion of the I-V characteristic between ion saturation current and the floating potential where the electron flux follows a simple exponential in $T_{e}$ and the ion saturation current is constant. The quality of the fitting is normally checked by an interactive program, and the routine provides density data from the probes that agrees very well with data from a Li-beam probe 28 .

\section{SCRAPE-OFF LAYER CHARACTERIZATION}

The scanning probe has been used to characterize the SOL parameters and e-folding lengths. The standard procedure is to position ALT at a fixed minor radius, retract the other TEXTOR limiters, and take several shots until reproducible discharges are achieved. The probe is then scanned during successive shots at $1 / 2 \mathrm{~cm}$ intervals from the main limiter location at $48 \mathrm{~cm}$ to within $1 \mathrm{~cm}$ of the ALT tangency point. The data presented in this section is with ohmic heating only. The profiles of the average ion saturation current, density, and electron temperature, evaluated at $0.8 \mathrm{sec}$, are shown in Fig. 5 for ALT at $40 \mathrm{~cm}$ and a constant line averaged density of $3 \times 10^{13} \mathrm{~cm}^{-3}$. The flux and density have the identical e-folding lengtis of about $2.2 \mathrm{~cm}$, but the $T_{e}$ profile is essentially flat. Equal flux and density e-folding lengths, and flat $T_{e}$ profiles, are 
characteristic of all the shots with ALT as the inain limiter. A model predicting flat electron profiles in the SOL, as observed in TEXTOR, has recently been published. ${ }^{29}$

A comparison of the scrape-off lengths for standard ohmic discharges with either ALT or the TEXTOR main limiters inserted is given in Table 1. Operation with the TEXTOR main limiters results in shorter scrape-off lengths compared with ALT because of the larger total poloidal angle subtended by the main limiters. The variation in density scrape-off length scales approximately with the square root of the average connection length to the limiters. Similar results have been obtained from Li-beam ${ }^{30}$ profiling of the SOL density in TEXTOR.

The variation in the SOL parameters with central line averaged density is shown in Fig. 6 for ALT at $40 \mathrm{~cm}$ and the probe positioned at $43 \mathrm{~cm}$. The flux to the probe at a fixed position is insensitive to changes in the core density. The electron temperature characteristically decreases with increasing core dersity. The values of the electron temperature have been observed to depend on the machine condition, and have varied over the range of $8-20 \mathrm{eV}$ with no auxiliary heating. High density, low $Z_{\text {eff }}$ discharges with carbonization typically have the lowest edge electron temperatures.

The SOL density and flux e-folding lengths do not vary significantly with core density or ALT position between 42 and $46 \mathrm{~cm}$. Fig. 7 shows $\lambda_{\mathrm{n}}$ derived from the scanning probe data and the Li-beam versus ALT position. Since the SOL density is position dependent and insensitive to the core density, as seen in Figs. 5 and 6, it follows that the scrape-off length for density also does not vary significantly during density scans. The value of $\lambda_{n}$ is typically found to be 1.8 $\pm 0.2 \mathrm{~cm}$ for ALT positioned from 42 to $46 \mathrm{~cm}$. Rough estimates of $\lambda_{\mathrm{n}}$ and $\lambda_{\Gamma}$ by the three throat probes in ALT-VG produce the same e-folding lengths as measured with the scanning probe. Similar scrape-off length measurements are expected 19 from these probes because the connection lengths to both the scanning probe and ALT are very long, and no direst shadowing by the limiter is observed. Interestingly, impurity scrape-off lengths of about $1.9 \mathrm{~cm}$, measured with collection probes, have been reported. ${ }^{31}$ The density scrape-off length measured with ALT positioned at $48 \mathrm{~cm}$ is less than $1.3 \mathrm{~cm}$, which is expected from the presence of other limiters located at that 
radius. When ALT is inserted to $40 \mathrm{~cm}, \lambda_{\mathrm{n}}$ increases to about $2.2 \mathrm{~cm}$. The tokamak is observed to disrupt much more frequently with ALT at this position. The longer scrape-off lengths and unstable operation may indicate a modification in the confinement associated with the reduction in safety factor, $q(a)$, with deep insertion of the limiter.

\section{V, PLASMA PARAMETERS AT ALT}

The probes on the ALT pump limiter modules measure the parameters of the plasma incident on the entrance slot. Information on the ion flux into the limiter is cnucial to understanding the particle removal efficiency and its scaling with edge plasma parameters such as density and electron temperature. Estimates of the total ion current into the pump limiter opening, the global particle confinement time and the power to ALT, for example, will be made in Section VII from the following measurements at ALT.

The average ion saturation current measured by the ion and electron side probes at one second into the pulse on the ALT-FG2 as it is inserted into TEXTOR is shown in Fig. 8. The line averaged core density was $3.3 \times 10^{13} \mathrm{~cm}^{-3}$, and the TEXTOR main limiters were retracted to 48 $\mathrm{cm}$. The ion side flux is a factor of 2 to 3 times the electron side flux depending on the position of ALT. The electron temperature on the ion and electron sides is roughly equal and increases as ALT is inserted, as shown in Fig.9. With ALT-FG2 located at $44 \mathrm{~cm}$, the variation in the collected fluxes with line averaged density is shown in Fig.10. As with the scanning probe, the flux does not change significantly with core density. However, the electron temperature, plotted in Fig.11, decreases by about a factor of two as the density is increased from 1.5 to $4 \times 10^{13} \mathrm{~cm}^{-3}$.

The probes on ALT-VG, which has only ion side collection but many more probes, give similar results to those on the ALT-FG2. The flux and electron temperature dependence on line averaged density for ALT-VG inserted to $42 \mathrm{~cm}$ is shown in Fig.12. The flux is fairly constant as the core density changes, and varies typically by about $25 \%$ over the core density range of 1 $5 \times 10^{13} \mathrm{~cm}^{-3}$. The electron temperature again decreases by a factor of two over this density range. The average local plasma density at the probe is about $2.8 \times 10^{12} \mathrm{~cm}^{-3}$, calculated from Eq. 1 and 
the data in Fig. 12 at an average core densiry of $3 \times 10^{13} \mathrm{~cm}^{-3}$. Since the density e-folding length is the same as the flux e-folding length over the slot opening, and electron temperature is shown in the figures, it is simple to calculate the local plasma density along the entrance of the slot for any core density. It is clear from the data shown here that at a given minor radius with ALT as the main limiter, the edge flux and density vary by only about a factor of a square root of 2 during TEXTOR density scans.

The effect of introducing pumping by ALT-I is to change the core density by reducing the recycling. 1,2 The SOL parameters follow the core density changes as described above, but are not significantly modified directly by the pumping. This is illustrated in Fig.13, where the ion saturation current to the EXALT probe is plotted versus the line averaged density for several different pumping speeds. Despite an increase in the pumping speed from $10001 /$ sec to 7,000 $1 / \mathrm{sec}$, the flux follows the same relationship with the core density. The flux measured by the EXALT probe is also shown to be the same at a given core density with the entrance flap open or closed. This means that the probe is sufficiently $\operatorname{close}^{19}$ to the limiter (1cm with the flap closed) or neutralizer plate $(25 \mathrm{~cm})$ to correctly measure the incident plasma flux. Since the pre-sheath length is estimated to be a few meters for the SOL plasma in TEXTOR, entrance probe measurements made $25 \mathrm{~cm}$ from the neutralizer plate are relatively deep in the pre-sheath potential and far from the flow stagnation region. Modifications in the flow velocity near bise throat region by fluid effects are not observed or expected.

The SOL electron temperature at a given core density is primarily determined by machine conditions, such as amount of carbonization and impurity level. In general, the local value of $\mathrm{T}_{e}$ at ALT increases by $2-5 \mathrm{eV}$ with pumping at a given core density, but any systematic dependence of $T_{e}$ with pumping speed has not been established. This is because $2 \mathrm{eV}$ is typically on the order of the reproducibility of the temperature measurements, and variations with machine conditions have been difficult to isolate. However, the se measurements indicate that the local plasm. density in the SOL is not decreased significantly during pumping by ALT. Strong modifications of the SOL plasma by pumping are not expected, in any case, because ALT removes only a small 
amount of the core efflux. The SOL plasma parameters are determined by global edge processes and not by small local changes due to ALT.

To check the poloidal symmetry of the flux into the slot, the EXALT probe and the middle probe of the three throat probes were positioned at the same minor radius, but near the top and bottom of the entrance of ALT-VG. Examinations of these probe fluxes have been made for core density scans at different ALT-I radial positions. There is no systematic variation in the poloidal symmetry of the flux into the slot over the extent of limiter opening.

\section{ICRH HEATING MODIFICATION OF THE BOUNDARY PLASMA}

ALT-I is located $45^{\circ}$ toroidally from two half turn ICRH antennae with an innermost radius of $48.8 \mathrm{~cm}$. Initial studies of the effect of ICRH heating on the SOL plasma are illustrated in Fig. 14 , which shows the average flux to ion and electron side probes for a plasma radius of $44 \mathrm{~cm}$, determined by ALT-FG2, and $n_{e}=3.4 \times 10^{13} \mathrm{~cm}^{-3}$. The ICRH heating pulse results in an increased flux of particles to both sides of ALT. The magnitude of the increase depends on the ICRH power level. The electron tempsrature in the SOL also increases during the low power heating pulse of Fig.14, from an initial value of $12 \mathrm{eV}$ to about $15-18 \mathrm{eV}$. Recent high power shots with $2 \mathrm{MW}$ of ICRH have resuited in electron temperature increases of over a factor of two to $26 \mathrm{eV}$. Systematic investigations are underway at this time to characterize the SOL modification with ICRH power level.

\section{DISCUSSION}

\section{a. Total Current Collected by ALT}

The total ion current into the purtip limiter opening can he calculated from the probe measurements of the flux, its radial scrape-off length, and its poloidal distribution. The total ion current into ALT, $I$, is then given by

$$
I=\int \Gamma_{\|} \mathrm{dA}=\int \mathrm{d} \theta \int \Gamma(\mathrm{r}) \mathrm{r} \mathrm{d} \mathbf{r},
$$


where the integrations are over the entrance openings, $\Gamma_{\|}$is the parallel flux in the SOL, $r$ is the minor radi:s, $A$ is the area of the entrance slot, $\theta$ is the poloidal extent of the opening. The radial flux dependence is

$$
\Gamma(\mathbf{r})=\Gamma_{\mathrm{a}} \exp \left[-(\mathbf{r}-\mathrm{a}) / \lambda_{\Gamma}\right]
$$

$\Gamma_{a}$ is the parallel flux at the limiter tangency point, $a$ is the minor radius to the ALT tangency point, and $\lambda_{\Gamma}$ is the flex scrape-off lenguh. For ALT, the slot subtends about $30^{\circ}$ of the poloidal arc. The parailel flux at the tangency point $i$, terms of the probe flux $\Gamma_{p}$ is simpiy

$$
\Gamma_{\mathrm{a}}=\Gamma_{\mathrm{p}} \exp \left(\mathrm{x} / \lambda_{\mathrm{r}}\right)
$$

where $x$ is the distance from the ALT tangency point to the piobe radius.

With the flux approximately poloidally symmetric, Eq. 2 is easily integrated over the entrances of the different ALT geometries to give

$$
I=\left.\Gamma_{2}\left[\left(r^{\prime}+a\right) \lambda_{\Gamma}+\lambda_{\Gamma} \Gamma^{2}\right\rceil \exp \left(-r^{\prime} / \lambda_{\Gamma}\right)\right|_{r_{1}} ^{r_{2}} \text {, }
$$

where $r_{1}$ and $r_{2}$ are the radii of the entrance slot edges. The total ion current into the entrance as a furction of the EXALT probe flux is calculated from Eq.5 in Table II for the different ALT modules with one sided collection only. If both sides of the ALT-FG2 are open for collection, then the total flux must have the weighted current from the electron side added. Note that two sided collection by ALT-FG2 at $44 \mathrm{~cm}$ is within $20 \%$ of the $88 \mathrm{~A}$ collected by the one sided ALTVG at $42 \mathrm{~cm}$. The comparable collection at different radii results from the shorter distance from the tangency point to the slot opening and two sided collection for ALT-FG2. This advantage of the ALT-FG2 geometry is offset by the high leading edge heat loading which limits the total power that the limiter can haudle. 


\section{b. Global Particle Confinement Time}

Probe measurements of the ion flux to the limiter, and the e-folding lengths, can be used to estimate the value of a giobal particle confinement time, $\tau_{\mathrm{p}}$, for the particles in the core plasma. The total core efflux can be expressed as

$$
\Gamma_{\mathrm{c}}=\mathrm{N}_{\mathrm{e}} / \tau_{\mathrm{p}}=\overline{\mathrm{n}}_{\mathrm{e}} \mathrm{V} / \tau_{\mathrm{p}}
$$

where $N_{e}$ is the total number of particles in the TEXTOR plasma, $\bar{n}_{e}$ is the line averaged core density, and $\mathrm{V}=2 \pi^{2} \mathrm{Ra}^{2}$ is the plasma volume. During ALT experiments in TEXTOR, $\mathrm{N}_{\mathrm{e}}$ found from integration ove the density profile is typically within $10 \%$ of $\bar{n}_{\mathrm{e}} \mathrm{V}$.

In the evaluation of $\tau_{p}$, we will use two models of the SOL plasma in an effort to bound the value of the core efflux in Eq. 6 from the probe information. As a first case, simply assume that the flux scrape-off length is constant up to the limiter tangency point. The total flux collected by the limiter is then

$$
\Gamma_{L}=\int d \theta \int \Gamma(r) r d r=\int d \theta \int \Gamma_{a} \exp \left[-(r-a) / \lambda_{\Gamma}\right] r d r,
$$

where the $\theta$ integration is over the limiter poloidal extent. This equation describes the collection on the ion or electron side, and the asymmetries are accounted for by integrating the flux to each side and adding for the total when evaluating $\Gamma_{\mathrm{a}}$. Since the ion side receives about 2.5 times the electron side flux in all cases with ALT, this evaluation can be accomplished by simply multiplying $\Gamma_{\mathrm{p}}$ (ion side) by 1.4. Integrating Eq.7 over the SOL from the tangency point to the TEXTOR liner resuits in

$$
\Gamma_{\mathrm{L}}=0.22 \pi \lambda_{\Gamma}\left(\mathrm{a}+\lambda_{\Gamma}\right) \Gamma_{\mathrm{a}}
$$

The total core effluxx is given by

$$
\Gamma_{C}=\Gamma_{L}+\Gamma_{W},
$$


where $\Gamma_{W}$ is the flux that missed the ALT limiter and hit the main limiters, the ICRH antenna guard ring, and the liner, $A$ calibrated $\mathrm{H}_{c}$ detector positioned to observe the main limiter at $\mathrm{a}=48$ $\mathrm{cm}$, and $\mathrm{H}_{\alpha}$ detector arrays observing the liner and antenna, indicate during ALT operation at $44 \mathrm{~cm}$ that $\Gamma_{\mathrm{W}}$ is about $1 / 3$ of $\Gamma_{\mathrm{L}}$. For ALT positioned between $\mathrm{a}=42$ and $44 \mathrm{~cm}$, the other limiters are 2.5-3 e-folding lengths behind the tangency point and ALT, therefore, collects a large fraction of the core efflux.

Generally, $\lambda_{\Gamma} / \mathrm{a}$ \& 1 , and Eqs. 6, 8 and 9 can be combined to express $\tau_{p}$ as

$$
\tau_{\mathrm{p}}=6.9 \pi \frac{\mathrm{Ra}_{\mathrm{a}} \bar{n}_{\mathrm{e}}}{\lambda_{\Gamma} \Gamma_{\mathrm{a}}} .
$$

While simply assuming a constant $\lambda_{\Gamma}$ over the entire SOL limits the accuracy of Eq.9, the scaling with machine and SOL parameters of interest is clearly illustrated. As shown in Sec.4 and 5, the flux to the probes does not vary significantly during a core density scan for a fixed ALT position. Therefore, $\tau_{p}$ scales linearly with the line averaged plasma density in TEXTOR.

It is possible to improve the simple model used above to calculate the total core efflux. The probes measure a constant $\lambda_{\Gamma}$ to within about $1-2 \mathrm{~cm}$ of the ALT tangency point. Recent analysis indicates that strong variations in the electron temperature exist at the limiter surface near the tangency point 28 . Additionally, Thomson scattering measurements show electron temperatures of $30-50 \mathrm{eV}$ near the tangency point for ALT at $44 \mathrm{~cm}$. A reasonable model 28 of this electron temperature variation is

$$
T_{e}(r)=T_{e 1} \exp \left[-(r-a) / \lambda_{T}\right]+T_{e 2},
$$

a pedestal model with $T_{e 2}$ equal to the probe measurements in the SOL, $T_{e 1}+T_{e 2}$ equal to the tangency point the tangency point electron temperature estimate, and $\lambda_{\mathrm{T}}=1 \mathrm{~cm}$. This approximate value of $\lambda_{\mathrm{T}}$ is suggestad by the heat flux measurements made on the face of ALT with IR cameras.

The probe and $\mathrm{Li}$ beam measurements give 


$$
n(r)=n_{a} \exp \left[-(r-a) / \lambda_{n}\right],
$$

which is assumed to be valid up to the tangency point. Since the flux scales as $n T_{e}^{1 / 2}$, the radial variation in flux is

$$
\Gamma(\mathrm{r})=\Gamma_{\mathrm{a}}\left(\mathrm{T}_{\mathrm{e} 1} / \mathrm{T}_{\mathrm{e}}(\mathrm{a})\right)^{1 / 2} \exp \left[-(\mathrm{r}-\mathrm{a}) / \lambda_{\mathrm{n}}\right]\left\{\exp \left[-(\mathrm{r}-\mathrm{a}) / \lambda_{\mathrm{T}}\right]+\mathrm{T}_{\mathrm{e} 2} / \mathrm{T}_{\mathrm{e} 1}\right\}^{1 / 2},
$$

valid for $r \geq a$. The limiter flux, from Eqs. 4 and 7, is then

$$
\Gamma_{\mathrm{L}}=0.68 \int \Gamma_{\mathrm{p}} \exp \left(x / \lambda_{\Gamma}\right)\left(\mathrm{T}_{\mathrm{e} 1} / T_{\mathrm{e}}(\mathrm{a})\right)^{1 / 2} \exp \left[-(\mathrm{r}-\mathrm{a}) / \lambda_{\mathrm{n}}\right]\left\{\exp \left[-(\mathrm{r}-\mathrm{a}) / \lambda_{\mathrm{T}}\right]+\mathrm{T}_{\mathrm{e} 2} / \mathrm{T}_{\mathrm{e} 1}\right\}^{1 / 2} \mathrm{rdr}
$$

This must be numerically integrated from the tangency point to infinity. The results are shown in Table III for some reasonable cases for the electron temperatures. The heat fluxes included in Table III will be calculated in the next section. The result of the simplified analysis of Eq.10 is recovered in the first example by proper selection of $T_{e 1}$ and $T_{e 2}$. It is interesting to note that a large variation in the electron temperature at the tangency point leads to only a $30 \%$ change in the evaluation of the core efflux, but almost a factor of four change in the heat flux.

It is now possible to calcuiate the particle confinement time by substituting the results from Eq.14 into Eqs. 6 and 9. Using the density scan data in Fig.10, and accounting for both the ion and electron sides, $\tau_{\mathrm{p}}$ is plotted in Fig. 15 versus the line averaged density. The range in the values of $\tau_{p}$ results from different the electron temperatures that we have used to estimate the total particle flux to the limiter in Table III. The highest values for $\tau_{p}$ are calculated assuming $T_{e}$ $=15 \mathrm{eV}$ and a flat electron temperature profile that extends to the tangency point. The lowest values for $\tau_{p}$ are for the extreme case of $T_{e}(a)=100 \mathrm{eV}$ and $\lambda_{T}=0.5 \mathrm{~cm}$. Values $f \mathrm{cr} T_{e}(a)$ from Thomson scattering and the limiter heat flux calculations (next section) are in the range of $30-$ $60 \mathrm{eV}$, and $\tau_{\mathrm{p}}$ is estimated to lie within the hashed area of Fig.15. The global particle confinement time is linearly proportional to the density over the density range from I to $4 \times 10^{13} \mathrm{~cm}^{-3}$. For comparison, $\tau_{\mathrm{E}}$ scaling typical of TEXTOR density scans ${ }^{32}$ is also plotted. The values of $\tau_{p}$ are on the order of and slightly larger than the energy confinement time. 
Scaling of $\tau_{\mathrm{p}}$ from $\mathrm{H}_{\alpha}$ intensity measurements over the volume of other tokamak plasmas have been reported. During ohmic heating in Alcator- $\mathrm{A}^{33}$ and JET ${ }^{34}, \tau_{\mathrm{p}}$ proportional to the core density was observed for $\overline{\mathbf{n}}_{\mathrm{e}}$ below a critical density. As the density was increased beyond this value, $\tau_{p}$ was found to decrease in both experiments. This behavior of $\tau_{p}$ at higher density was interpr ted to be caused by the edge plasma becoming opaque to neutrals. Recyeling then takes plsce predominantly in the edge, decoupling $\tau_{\mathrm{p}}$ from the core plasma. In IEXTOR, the ionization mean-free-path for $1-2 \mathrm{eV}$ H neutrals from the limiter surface $\mathrm{e}^{35}$ is estimated to be on the order of $10 \mathrm{~cm}$ for the highest core densities of Fig.10. This is not sufficiently short to confine the recycling to only the edge plasma, indicating that the critical density has not yet been achieved. Therefore, the behavior of $\tau_{p}$ observed from the probe measurements follows the same density scaling reporled from $\mathrm{H}_{\alpha}$ measurements in other machines in the proper density range.

It is of interest to apply this analysis from the probe data for $\tau_{p}$ during ICRH heauing. From Eq.9, $\tau_{\mathrm{p}}$ is seen to scale inversely with both the probe flux and SOL flux e-folding length. The data in Fig. 14 during ICRH shows that the probe flux is proportional to the power coupled to the plasma. The edge e-folding lengths are also observed ${ }^{17,32}$ to broaden during ICRH heating. It follows that $\tau_{p}$ decreases as the ICRH power level increases. The reductions in $\tau_{p}$ are estimated from initial studies to be similar to the changes in $\tau_{E}$ reported ${ }^{4}$ during ICRH heating.

\section{c. Limiter Heat Flux}

The parallel heat flux density to the ALT limiter is given by

$$
\mathrm{q}(\mathrm{r})=\gamma_{5} T_{\mathrm{e}}(\mathrm{r}) \Gamma_{\mathrm{p}}(\mathrm{r}), \quad \mathrm{r} \geq \mathrm{a}
$$

where $\gamma_{s}$ is the total sheath transmission factor for ions and electrons. For the assumption of equal ion and electron temperatures, $\gamma_{s}$ is calculated ${ }^{27}$ to be 6.5 . Utilizing the pedestal model with Eqs. 11 and 13, the total heat flux to the limiter is

$$
Q=4.5 \int \Gamma_{p} \exp \left(x / \lambda_{\Gamma}\right) T_{e 1}^{3 / 2} T_{e}(a)^{-1 / 2} \exp \left[-(r-a) / \lambda_{n}\right]\left\{\exp \left[-(r-a) / \lambda_{T}\right]+T_{e 2} / T_{e 1}\right\}^{3 / 2} T d r
$$


The results of a numerical integration of Eq. 16 are included in Table III for $a=44 \mathrm{~cm}$. Estimates of the power to ALT at this radius from thermocouple measurements of the bulk temperature rise indicate that ALT typically receives $10-30$ percent of ohmic power. This is in reasonable agreement with the values calculated in Table III for $\mathrm{T}_{\mathrm{e}}(\mathrm{a})$ on the order of $50 \mathrm{eV}$.

Detailed analysis ${ }^{36}$ of the heat flux to ALT, as measured by an IR camera, ${ }^{3}$ has been made for the limiter positioned at $40 \mathrm{~cm}$. AlT is typically found to collect $150 \mathrm{~kW}$ of power during this deep insertion into the plasma. The EXALT probe flux during these runs was $1.4 \mathrm{~A} / \mathrm{cm}^{2}$. Using the ion to electron side asymmetry of 3 to 1 and density e-fioldings of $2.2 \mathrm{~cm}$, the power to ALT calculated from Eq. 16 is shown in Fig.16. Two possible temperature e-folding lengths are shown. The electron temperature required at the tangency point to predict the measured $150 \mathrm{~kW}$ power deposition is about $50-60 \mathrm{eV}$. This is in good agreement with the values estimated from Thomson scattering. If the flat $\mathrm{T}_{e}$ profile with $15 \mathrm{eV}$ up to the tangency point is used, the power deposition is a factor of three too low. The pedestal model with a reasonable value for $T_{e}(a)$ predicts the correct power flux to ALT.

\section{d. Perpendicular Diffusion Coefficient}

From probe measurements, a simple estimate of the perpendicular diffusion coefficient, $D_{\perp}$, in the SOL plasma can be made. The average core efflux over the plasma surface area $S$ is equal to the perpendicular flux at the edge,

$$
\underset{S}{\Gamma_{c}}=-\nabla \Gamma_{i}=D_{\perp} \frac{d n}{d r}
$$

Approximating the gradient scale length as $n_{e}(a) / \lambda_{n}$, using Eqs. 8 and 9 for the core efflux, and taking $\lambda_{\Gamma}$ equal to $\lambda_{\pi}$, the perpendicular diffusion coefficient is

$$
\mathrm{D}_{\perp}=\frac{\lambda_{\pi}^{2} \Gamma_{\mathrm{a}}}{14 \pi R \mathrm{n}_{\mathrm{e}}(\mathrm{a})} .
$$


From the expression for the ion current term in Eq.1, the flux $\Gamma_{\mathrm{a}}$ is $n_{\mathrm{e}}(\mathrm{a}) \mathrm{c}_{\mathrm{s}} / 2$, and Eq. 18 becomes

$$
D_{\perp}=\lambda_{n}^{2} c_{s} / 28 R,
$$

where $c_{s}$ is evaluated at the limiter tangency point. If we assume that the electron temperature at the limiter tangency poiat is $30 \mathrm{eV}$, and the edge density scrape-off length is $1.8 \mathrm{~cm}$, then the perpendicular diffusion coefficient from Eq.12 is $5.1 \times 10^{3} \mathrm{~cm}^{2} / \mathrm{sec}$. The Bohm diffusion coefficient evaluated for this value of $\mathrm{T}_{\mathrm{e}}$, and TEXTOR magnetic field of $2.0 \mathrm{~T}$, is $9.4 \times 10^{3}$ $\mathrm{cm}^{2} / \mathrm{sec}$. Within the accuracy of this simple calculation the diffusion of the edge plasma is consistent with Bohm diffusion values.

\section{d. Pump Limiter Physics}

Measurements of the plasina parameters in the ALT throat provide information on the physics which occurs in the pump limiter. As shown above, typical plasma densities of 1$5 \times 10^{12} \mathrm{~cm}^{-3}$ and electron ternperatures of $8-25 \mathrm{jV}$ are measured by the probes on ALT. The electron temperature inside the throat region is essentially unchanged from the edge plasma in the boundary of TEXTOR. Fig.17 shows $T_{e}$ from the probe at the neutralizer plate plotted against $T_{e}$ found from the EXALT probe during the density scans of Fig.13. No consistent difference in the electron temperature is found. Since the EXALT and scanning probe values of $T_{e}$ are generally the same, Fig.17 indicates that the recycling which occurs at ALT and the neutralizer plate does not strongly modify the local plasma. This result has led to recent modeling of ALT ${ }^{37}$ which assumes constant plasma parameters in the throat region, and which correctly predicts the pressure rise in the pump limiter. 


\section{Summary}

Langmuir probes have been used to determine the total flux into the pump limiter and the local density and electron temperature in the SOL and limiter throat. In TEXTOR, equal density and flux scrape-off lengths of about $1.8 \mathrm{~cm}$ have been measured while ALT is the primary limiter positioned between $42-46 \mathrm{~cm}$. These e-folding lengths increase to over $2.2 \mathrm{~cm}$ when ALT is inserted to $40 \mathrm{~cm}$. The perpendicular diffusion ccefficient in the boundary of TEXTOR is found to be consistent with Bohm diffusion, and is about $5 \times 10^{3} \mathrm{~cm}^{2} / \mathrm{sec}$. Flat electron temperature profiles in the SOL are observed for all ALT experimerts with ohmic heating, with $T_{e}$ ranging from 8 to $20 \mathrm{eV}$. The electron temperature characteristically decreases as the core plasma density is raised during density scans.

The flux to the probes in the shadow of the limiter is insensitive to the core density, indicating that $\tau_{\mathrm{p}}$ is proportional to $\overline{\mathrm{n}}_{\mathrm{e}}$ over the density range of these experimets. This behavior of $\tau_{p}$ has been observed from $\mathrm{H}_{\alpha}$ measurements in other machines below a critical density at which the recycling becomes localized in the edge. It appears that this critical density was not achieved during the experiments reported here. The values of $\tau_{p}$ estimated from the ALT probe measurements agree remarkably well (within about 20\%) with recently published values by Samm ${ }^{30}$ derived from separate $H_{\alpha}$ and spectroscopic measurements in TEXTOR. The pedestal model, and the IR camera measurements of the power loading, to ALT, resslts in predictions of tangency point electron temperatures of about $50 \mathrm{eV}$, in good agreement with the measurements by Thomson scattering.

The fact that $\tau_{E}$ scaies with $\tilde{n}_{e}$ in the ohmic heating phase implies that $\tau_{p}$ is proportionai to $\tau_{E}$. Systematic investigations of this confinement time behavior during ICRH auxiliary heating are now underway. However, $\tau_{p}$ is found, in the initial experiments reported here, to decrease with increasing ICRH power. This is consistent with the observed decrease of $\tau_{E}$ with ICRH power, although a scaling law of $\tau_{p}$ with ICRH heating is not yet available.

Finally, pump limiter operation does not directly affect the SOL plasma during ohmic heating. Operation with pumping and particle removal decreases the line averaged core plasma 
density by changing the recycling at the boundary. The flux to the limiter and the edge $T_{e}$ follow the changes in the core density.

\section{ACKNOWLEDGMENTS}

The authors would like to thank Dr. R.Zuhr of ORNL for the use of the scanning probe drive, Dr. Y.T.Lie for the Li-beam data analysis, Dr. IJ.Samm for discussions on the TEXTOR edge plasma, the TEXTOR team for support of these experiments, the scientists from the Laboratotie de Physique des Plasmas, Ecole Royale Militaire, Brussels, Belgium for the ICRH system operation, and Mr. K. A. Andrews, Mr. T.Sketchely, Mr. V.Low, Mr. A. Hiller, Mr. S. Guthrie, and M:: L. Brown for technical support of the ALT-I project.

* Work supported by the U.S. Department of Energy under contract \#DE-F603-85 ER 51069, and by Sandia National Laboratories under contract \#51-7706. 


\section{REFERENCES}

1. A.E.Pontau, et al., J. Nucl. Mat., $128 \& 129,434$ (1984),

2. K.H.Dippel, et al., Plasma Physics and Controlled Nucl. Fusion Research (Proc. 10 Intl. LAEA Conf., London 1984), Vol. 1, IAEA Vienna (1935).

3. G.J.Thomas, et al., J. Vac. Sci. Tech, Proc. American Vac. Soc., Fusion Tech.

Div. Meeting, Houston, Texas (1985), to be published.

4. J.Schluter, et al., and V.P.Bhatnagar, et al., Nucl. Fusion, 25, 1065 (1985).

5. R. Budny, J. Vac. Sci. Tech., 20, 1238 (1982).

6. R. Budny and D. Manos, J. Nucl. Mat, 121, 41 (1984).

7. A.J. Wootton, K.E.Yokoyama, and P.H. Edmonds, ORNL Report TM-8938, (1985).

8. G.M.McCracken, et al., J.Nucl.Mat.,128\&129, 150 (1984).

9. G.Proudfoot, P.J.Harbour, J.Allen, A.Lewis, J.Nucl.Mait,128\&129, 180 (1984).

10. M. El Shaer, "Probe Measurements in the ASDEX Boundary Layer and the Eifect of Neutral Beam Injection and Lower Hybrid Heating," Max-Plank Institut fur Plasmaphysikk Report, IPP WI/96, Garching bei Munchen, April 1984.

11. B.LaBombarci, et al., Bull.Am.Phys.Soc.,30,1413 (1985).

12. D.Manos, R.V.Budiny, S.A.Cohen, J.Vac.Sci.Tech. A, 1, 845 (1983).

13. R.Budny, et al., Bull. Am. Phys. Soc., 30, 1523 (1985).

14. S.Talmadge, et al., Nucl. Fusion, 22 , 1369 (1982).

15. R.Budny, et ai., "Initial Results from the Scoop Limiter Experiment in PDX", Plasma Physics Laboratory Report, PPPL-2061, Princeton University, Dec.1983.

16. P.K.Mioduszewski, et.al., J.Nucl.Mat., 121, 285 (1984).

17. A.M.Messiaen, et.al.. Plasma Physics and Controlled Fusion, 28, 71 (1986).

18. J. Winter, et aI., J.Nucl.Mat,,128\&122, 841 (1984).

19. P.C. Stangeby, J. Phys. D: Appl. Phys.,18, 1547 (1985).

20. R.A.Zuhr, Proc. 8th Conf. on Appl. of Accelerators in Research and Industry, November 12-14, 1984, Denton, Texas. 
21. W.R.Wampler, to be published.

22. F.F.Chen, "Electric Probes," in Plasma Diagnostic Techniques, edited by R.H.Huddelstone and S.L.Leonard (Academic Press, New York) p.113-200.

23. P.C.Stangeby, J.Phys. D, 15, 1007 (1982).

24. P.C.Stangeby, Phys, Fluids, 27,682 (1984).

25. P.C.Stangeby, J. Nucl. Mat., $128 \& 129,969$ (1984).

26. P.C.Stangeby, J. Nucl. Mat., 121,36 (1984).

27. P.C.Stangeby, Phys. Fluids, 28,644 (1985).

28. E.Hintz and P.Bogen, J.Nucl.Mat,128\&129, 229 (1984).

29. A.K.Prinja and R.W.Conn, J.Nucl.Mat.,128\&129, 135 (1984).

30. U.Samm, et al., Proc. IEEE Conf.Plasma Sci., Austin, Texas, Nov. 1985, to be published in IEEE Joumal of Plasma Science, 1986.

31. R.A.Zuhr and W.R.Wampler, J. Vac. Sci. Tech., Proc. 31st Natl. Symp. Ameriacn Vac. Soc., Reno, Nevada, Dec. 4-7, 1984.

32. G. Waidmann, et al, Plasma Physics and Controlled Nucl. Fusion Research (Proc. $10^{\text {th }}$ Intl. IAEA Conf, London 1984), Vol, 1, IAEA Vienna (1985).

33. E.S.Martar, J. Nucl. Mat, 76\&77, 59 (1978).

34. J.G.Cordey, et al, Plasma Physics and Controlled Nucl. Fusion Research (Proc. 10th Intl. LAEA Conf., London 1984), Vol. 1, IAEA Vienna (1985).

35. S.A.Cohen, J. Nucl. Mat., 76\&77, 68 (1978).

36. R. McGrath, to be published.

37. G.A.Campbell, et al, submitted to Phys.Rev.Lett, April 1986. 
TABLE I. Comparison of the scrape-off lengths for standard limiter positions in TEXTOR.

$\begin{array}{cccc}\text { ALT Position } & \text { Main Limiters } & \lambda_{\mathrm{n}} & \lambda_{\mathrm{Te}} \\ \text { (cm) } & (\mathrm{cm}) & (\mathrm{cm}) & (\mathrm{cm}) \\ 44 & 48 & 1.9 & >10 \\ 50 & 45 & 1.3 & 4.5\end{array}$

TABLE II. Tctal ion current into one side of the ALT module openings as a function of the measured probe fluxes for several standard positions.

\begin{tabular}{|c|c|c|c|c|c|}
\hline MODULE & $\begin{array}{c}a \\
(\mathrm{~cm})\end{array}$ & $\begin{array}{c}x \\
(\mathrm{~cm})\end{array}$ & $\begin{array}{l}\lambda_{\Gamma} \\
(\mathrm{cm})\end{array}$ & $\begin{array}{c}\text { Geometric Area } \\
\left(\mathrm{cm}^{2}\right)\end{array}$ & $\begin{array}{c}\text { I } \\
\text { (Amperes) }\end{array}$ \\
\hline ALT-VG & 40 & 3.5 & 2.25 & 69 & $67.7 \Gamma_{p}$ \\
\hline ALT-VG & 42 & 3.5 & 1.8 & 69 & $73.8 \mathrm{r}_{\mathrm{P}}$ \\
\hline ALT-VG & 44 & 3.5 & 1.8 & 69 & $77.1 \Gamma_{p}$ \\
\hline ALT-FG2 & 43 & 2.0 & 1.8 & 48 & $45.2 \Gamma_{p}$ \\
\hline ALT-FG2 & 44 & 2.0 & 1.8 & 48 & $46.2 \Gamma_{p}$ \\
\hline
\end{tabular}


TABLE III. Particle and heat fluxes calculared for ALT-FG2 operation for reasonable values of the electron temperatures in the pedestal mode!.

$$
a=44 \mathrm{~cm} \quad \lambda_{n}=1.8 \mathrm{~cm} \quad P_{\mathrm{OH}}=350 \mathrm{~kW} \quad \mathrm{~T}_{\mathrm{e}}(\mathrm{a})=\mathrm{T}_{\mathrm{e} 1}+\mathrm{T}_{\mathrm{e} 2} \quad \Gamma_{\mathrm{p}}=1.3 \mathrm{~A} / \mathrm{cm}^{2}
$$

\begin{tabular}{ccccccc}
\hline $\mathrm{T}_{\mathrm{e} 1}$ & $\mathrm{~T}_{\mathrm{e} 2}$ & $\lambda_{\mathrm{T}}$ & $\Gamma_{\mathrm{a}}$ & Tota1 Efflux & Total Heat Flux & \%Ohmic \\
$(\mathrm{eV})$ & $(\mathrm{eV})$ & $(\mathrm{cm})$ & $\left(\mathrm{A} / \mathrm{cm}^{2}\right)$ & $\begin{array}{c}\text { (particles/sec) } \\
\text { (kilowatts) }\end{array}$ & $(\%)$ \\
15 & 0 & $\infty$ & 4 & $1.33 \times 10^{21}$ & 21.4 & 6.1 \\
25 & 15 & 1 & 5.8 & $1.5 \times 10^{21}$ & 41.1 & 11.7 \\
35 & 15 & 1 & 6.3 & $1.55 \times 10^{21}$ & 49.5 & 14.1 \\
85 & 15 & 0.5 & 9.7 & $1.76 \times 10^{21}$ & 78.1 & 23.3
\end{tabular}




\section{FIGURES}

1. ALT-VG schenratic view indicating the general geometry and the probe locations.

2. ALT-FG2 schematic view showing only the head and the location of the two probes, each on the horizontal midplane and facing in the ion and electron drift directions.

3a. Design of the fixed probes attached to the ALT modules. Large probe design was determined by the power loading expected in TEXTOR.

3b. Geometry of the scanning probe head and the probe electrode. The probe body was allowed to float relative to the rest of TEXTOR.

4. Standard shot showing the line average density in TEXTOR and the ion saturation current collect by the EXALT probe on ALT.

5. Profiles of the flux, density and $T_{\mathrm{e}}$ versus radius from the scanning probe. Data was taken with a constant line averaged core density of $3 \times 10^{13} \mathrm{~cm}^{-3}$, ALT positioned at $40 \mathrm{~cm}$, and the main limiters retracted to $48 \mathrm{~cm}$. The values of $\lambda_{\Gamma}$ and $\lambda_{\Re}$ are characteristicly equal in the $S O L$.

6. Scanning probe flux, density, and electron temperature versus line averaged core density for ALT at $40 \mathrm{~cm}$ and the probe at $43 \mathrm{~cm}$.

7. Density e-folding length in the SOL versus position of the ALT limiter. The value of $\lambda_{n}$ does not change with ALT position between 42 and $46 \mathrm{~cm}$, and increases only when ALT is inserted to $40 \mathrm{~cm}$. Data from the scanning probe agrees well with the $\mathrm{L} i$-beam values.

8. Ion and electron side probe flux versus ALT-FG2 position. Data was taken for a constant line averaged density of $2 \times 10^{13} \mathrm{~cm}^{-3}$.

9. Electon temperature from the ion and electron side probes as ALT-FG2 is inserted into the plasma with a line averaged density of $3 \times 10^{13} \mathrm{~cm}^{-3}$.

10. Density scan dependence of the probe fluxes on the ion and electron sides of ALT-FG2 at a position of $44 \mathrm{~cm}$.

11. Electron temperature measured by the ion and electron side probes during a density scan with ALT-FG2 inserted to $44 \mathrm{~cm}$. 
12. Flux and electron temperature measured by the EXALT probe for ALT-VG at $42 \mathrm{~cm}$ during a density scan.

13. EXALT probe flux to ALT-VG for a scan of the line averaged core density. Variations in the pumping speed and flap position do not change the measured flux at a given core denșity.

14. Average probe current on the ion and electron facing sides during ICRH heating. The measured flux increase is proportional to the ICRH power level.

15. The global particle confinement time $\tau_{p}$ and energy confinement time $\tau_{E}$ in TEXTOR versus the line averaged density, evaluated from the probe measurements in the SOL. Range in $\tau_{p}$ results from uncertainity in the electron temperature profile near the limiter surface when evatuating the total core efflux.

16. Power deposition on ALT at $40 \mathrm{~cm}$ calculated from the probe data and the pedestal model. IR camera measurements indicated that about $150 \mathrm{~kW}$ is actually deposited, indicating that $\mathrm{T}_{\mathrm{e}}(\mathrm{a})$ is about $50-60 \mathrm{eV}$.

17. The electron temperature measured at the neutralizer plate probe versus the electron temperature from the EXALT probe. The value of $T_{e}$ is essentially constant along the field line in the ALT throat inspite of recycling occuring at the neutralizer plate. 


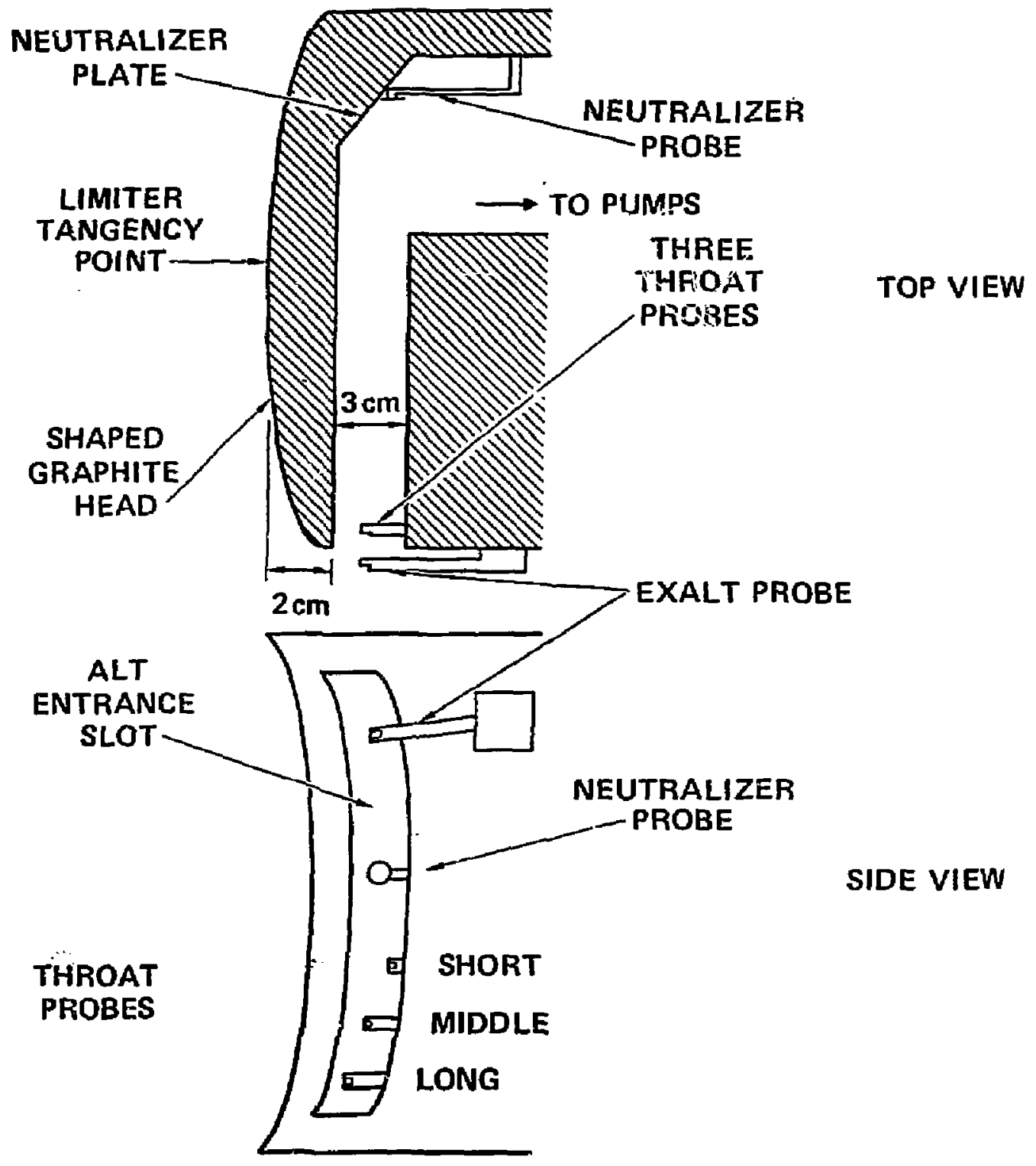

Figure 1 


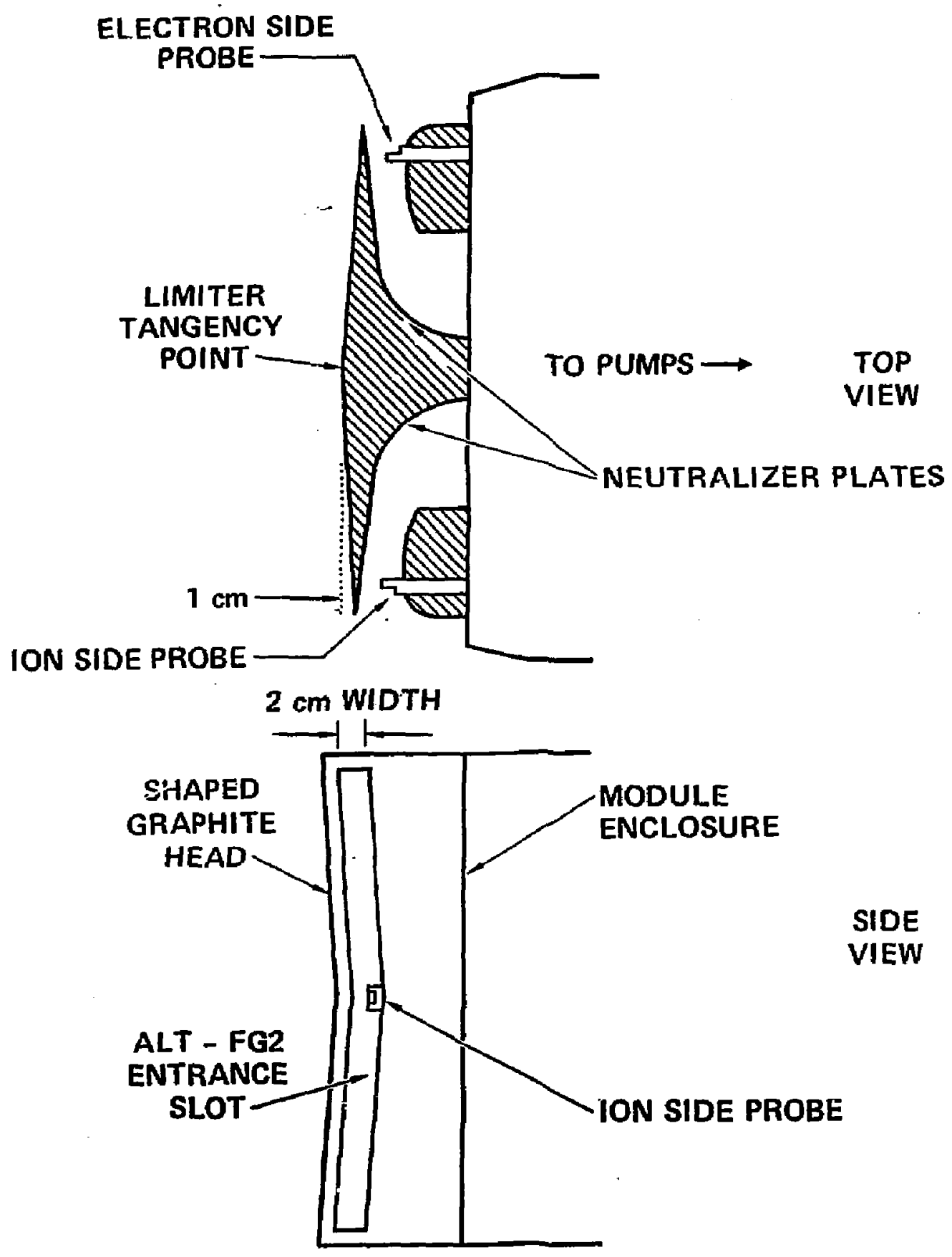




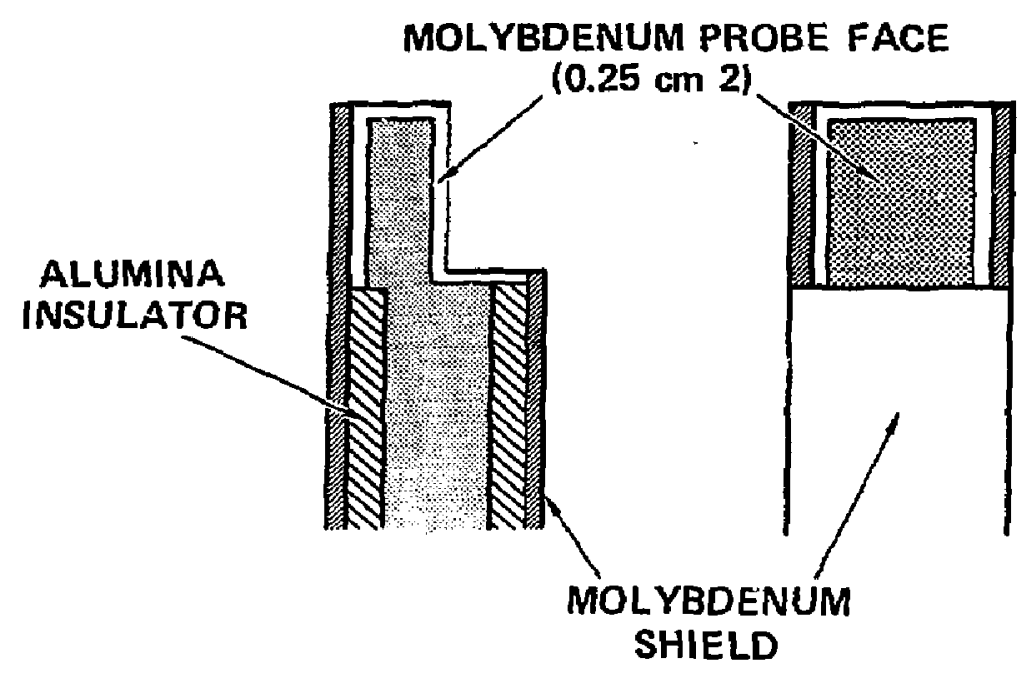

(a)

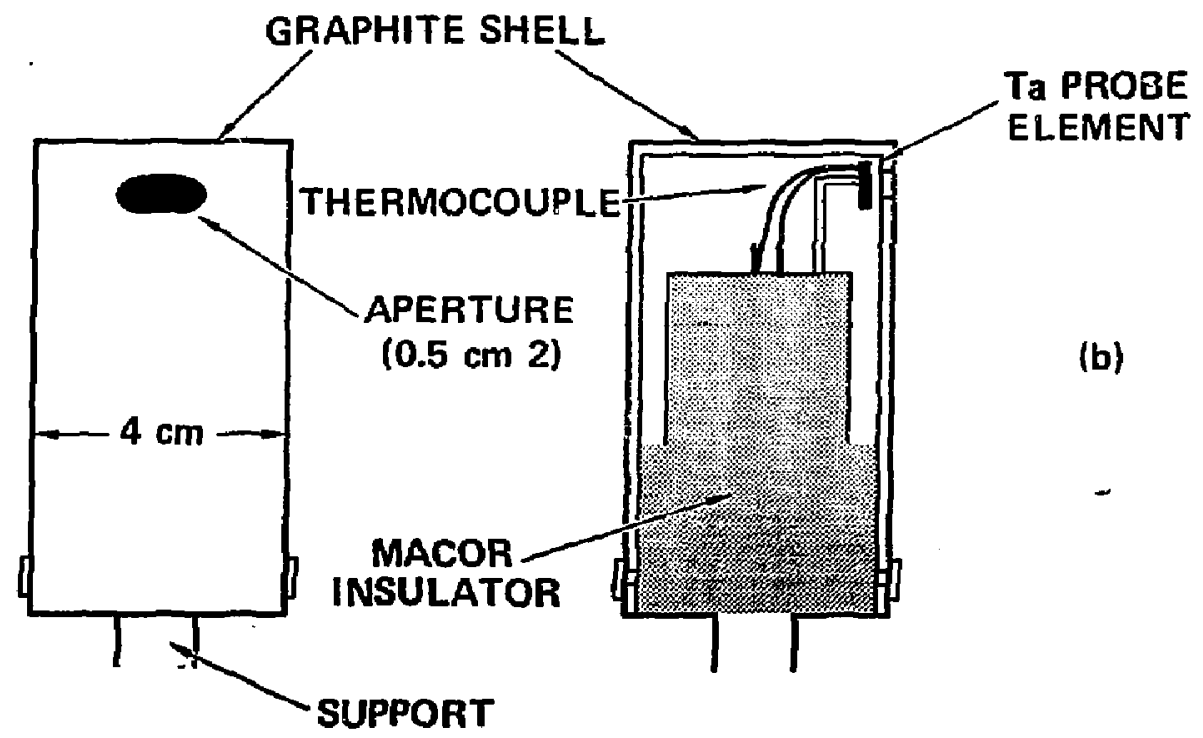



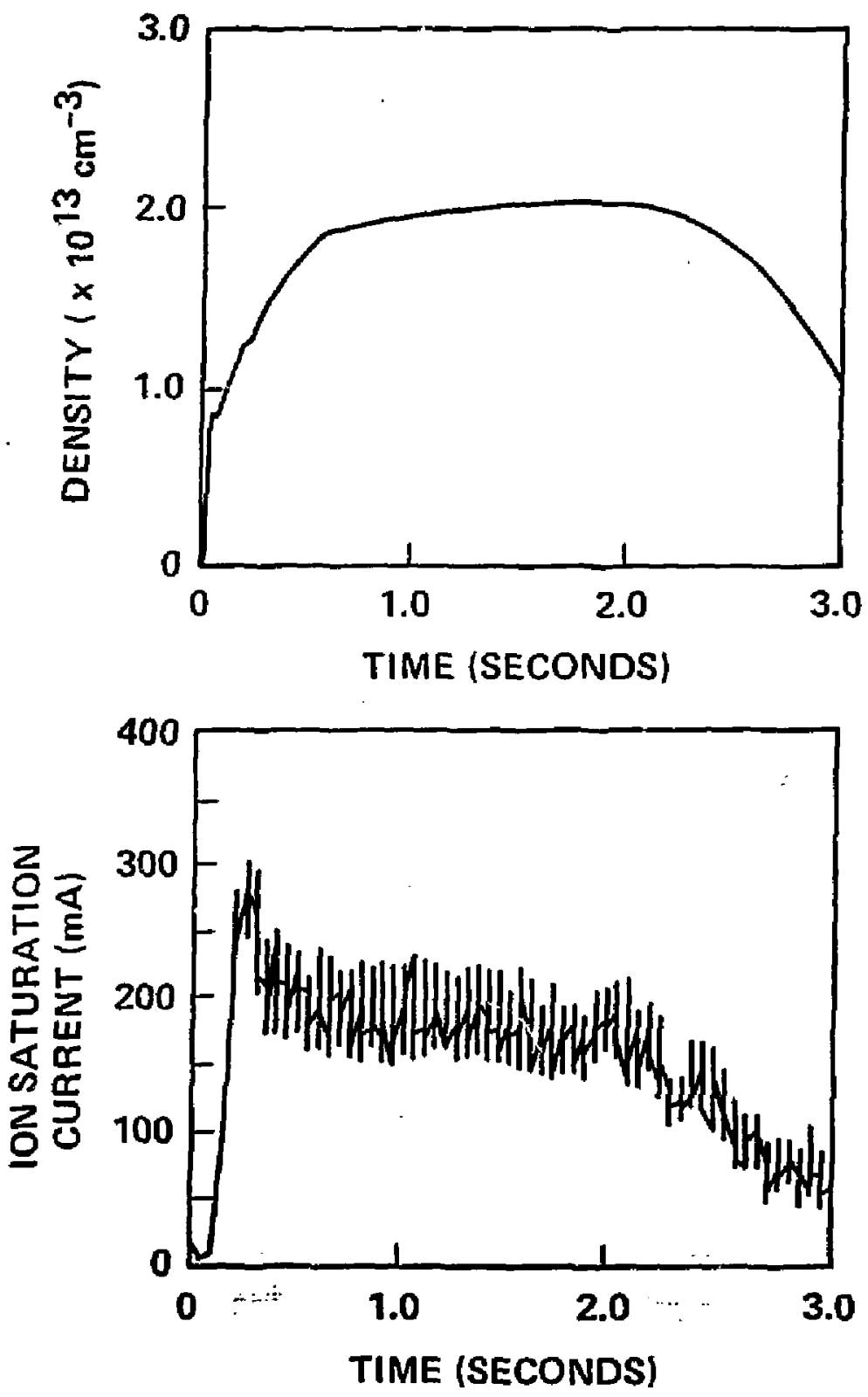

F1gure 4 
5 วมกรF这

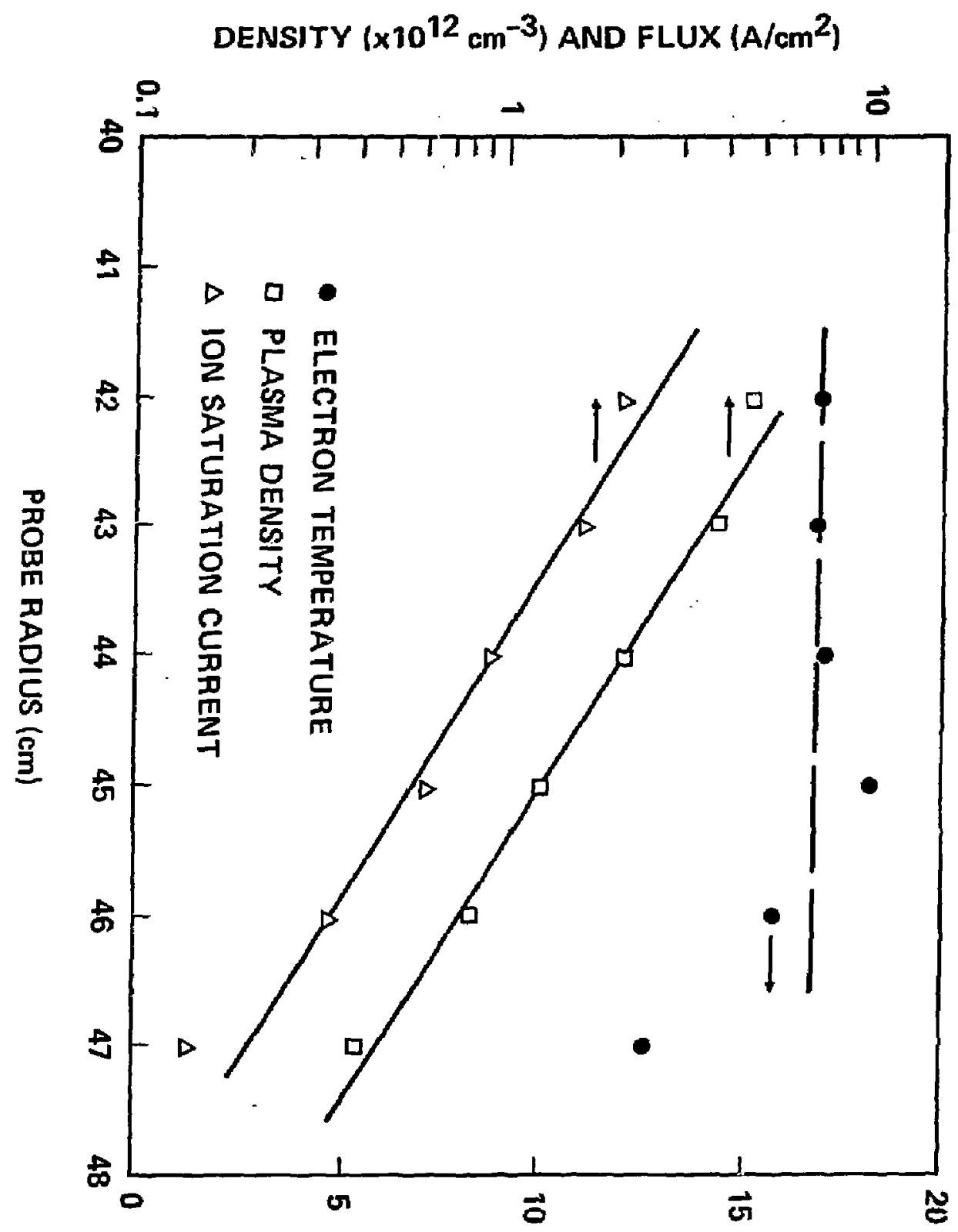

ELECTRON TEMPERATURE (eV) 


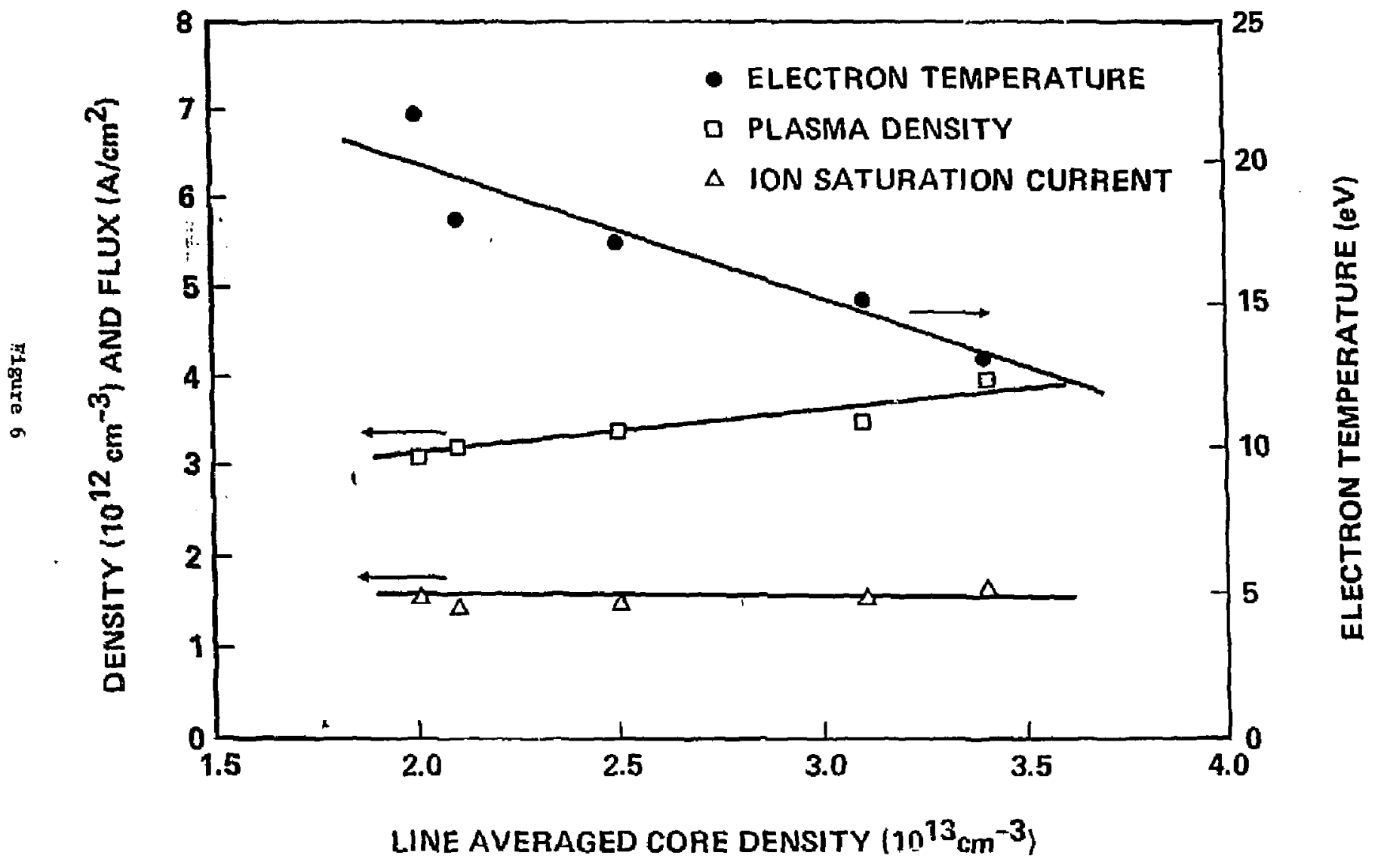




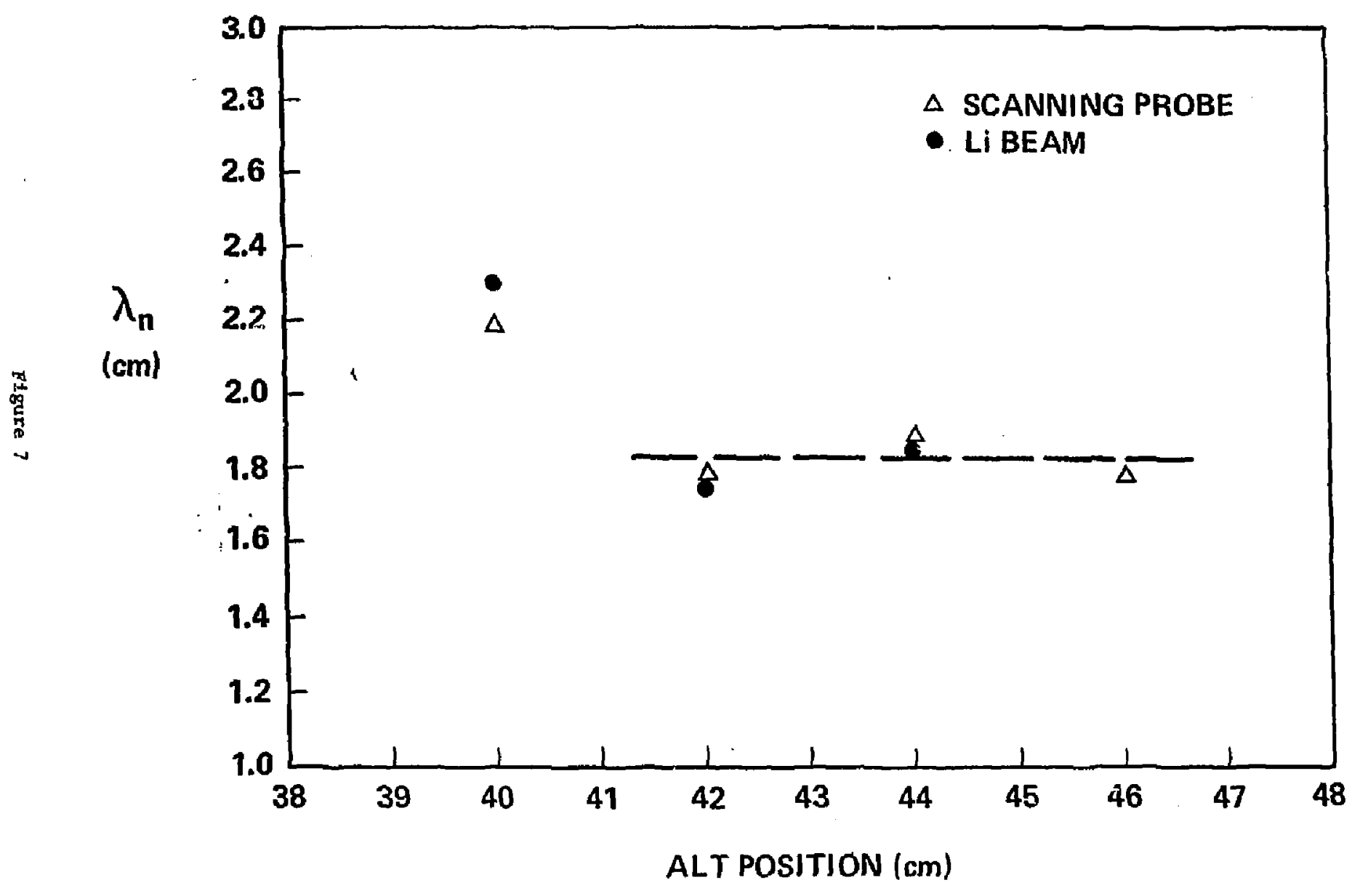




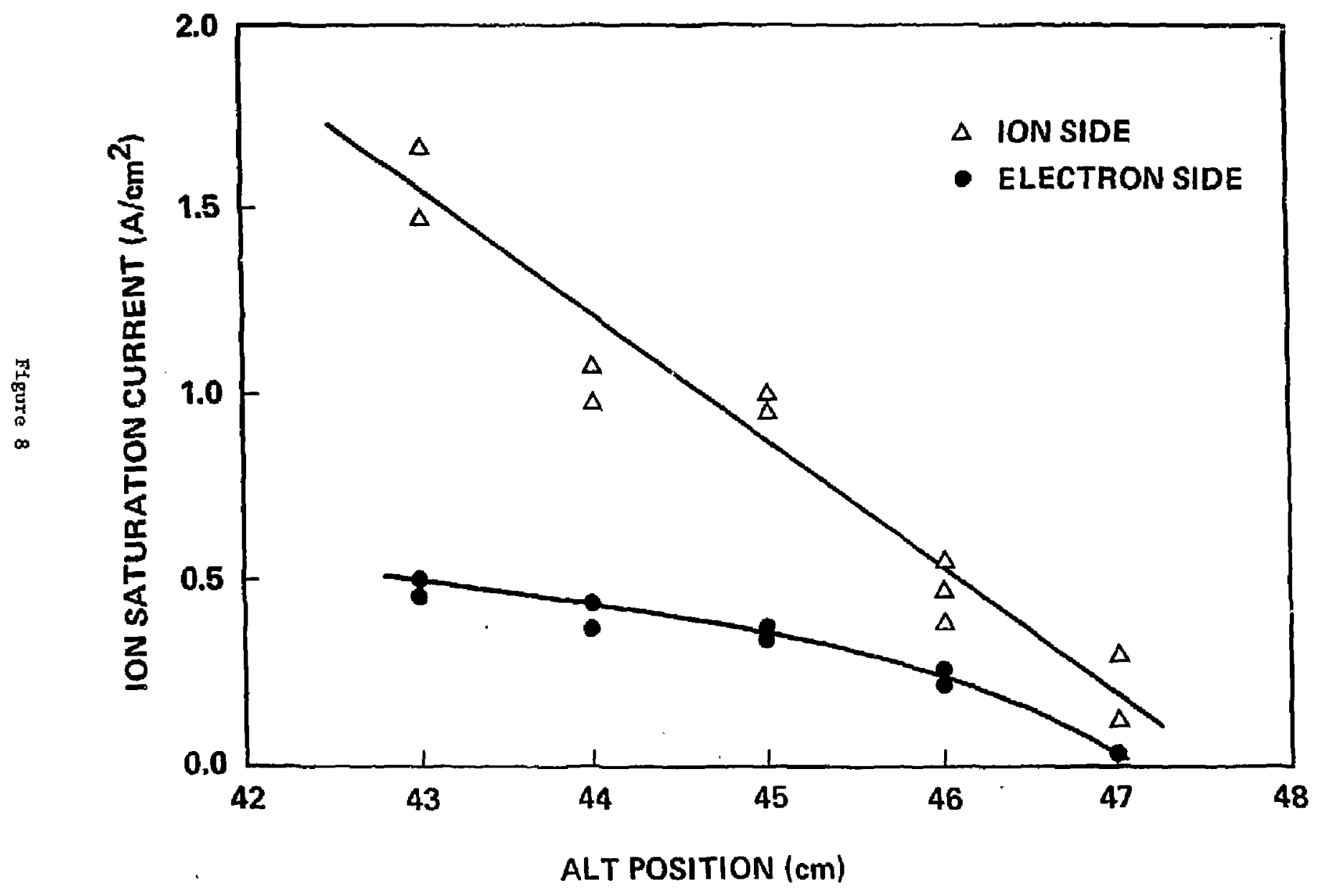


6 aมnรtTa

\section{ELECTRON TEMPERATURE (eV)}

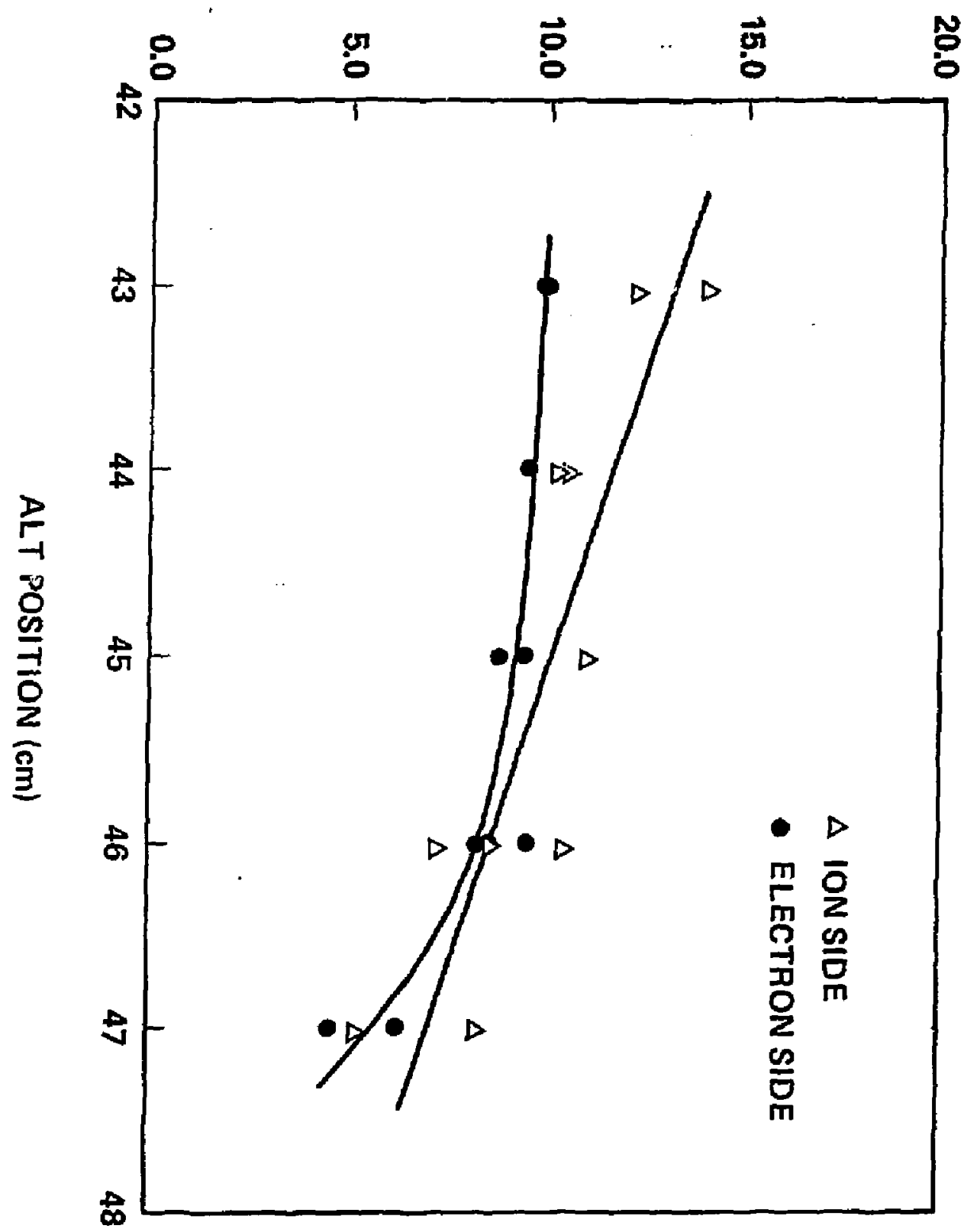




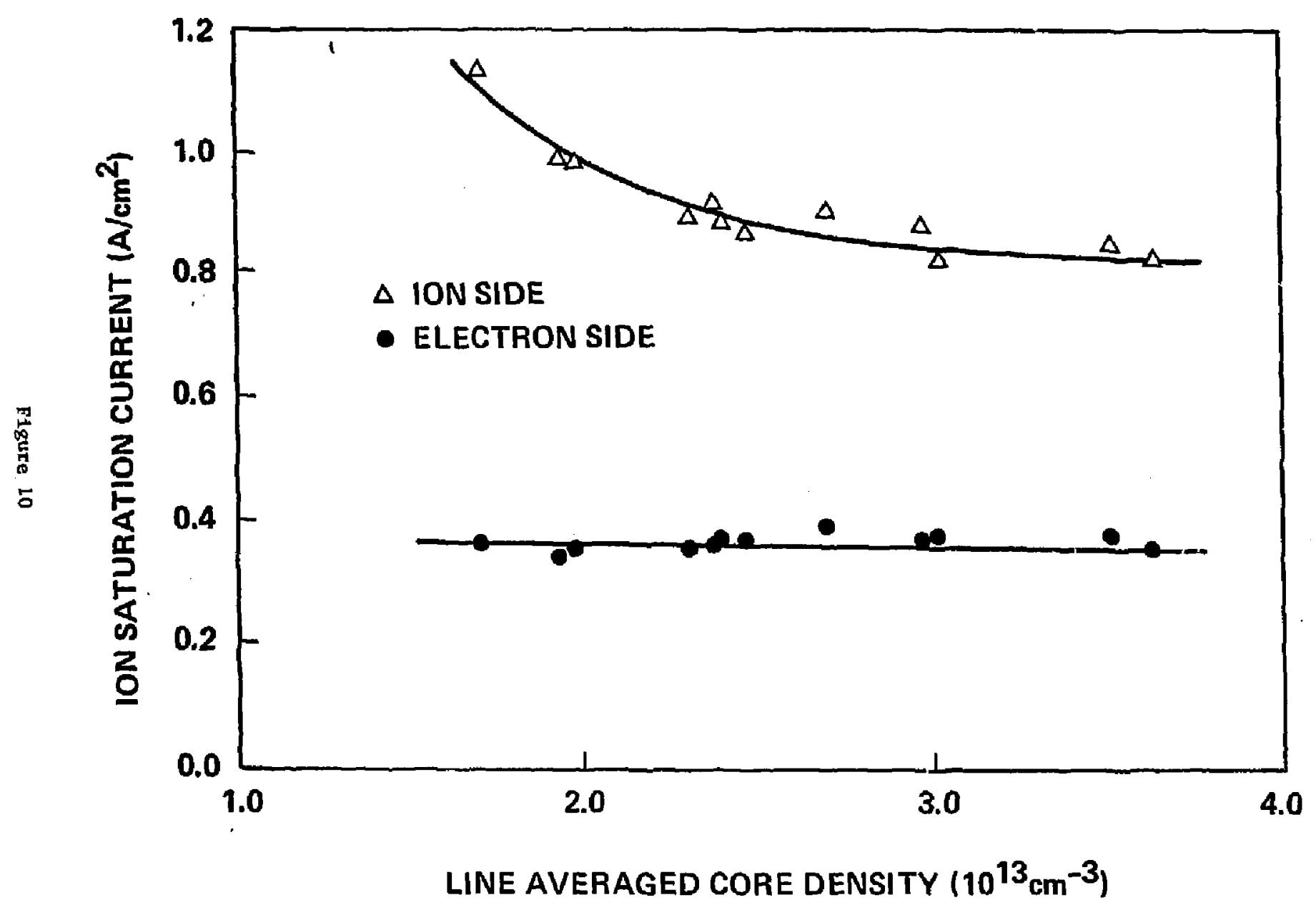




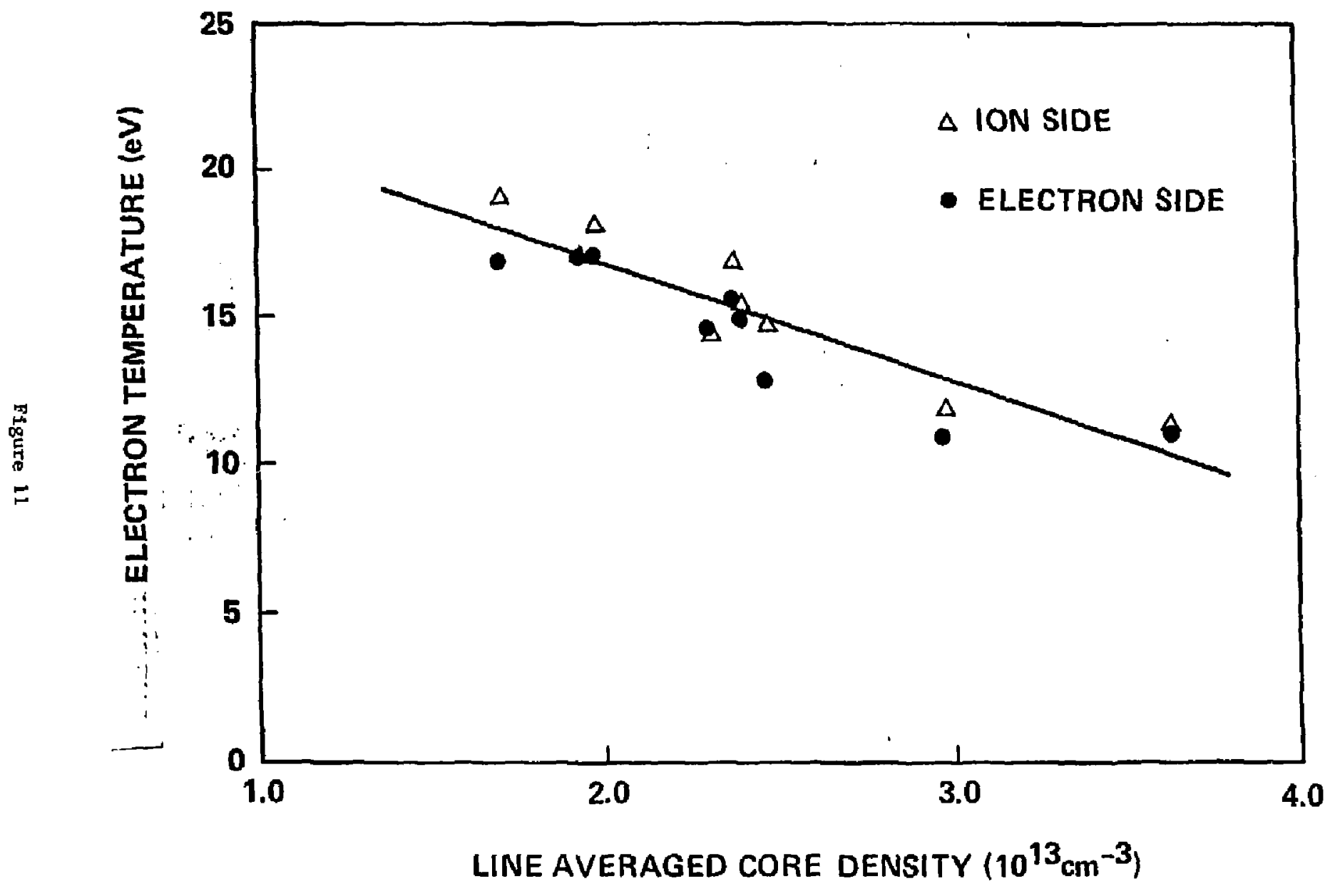




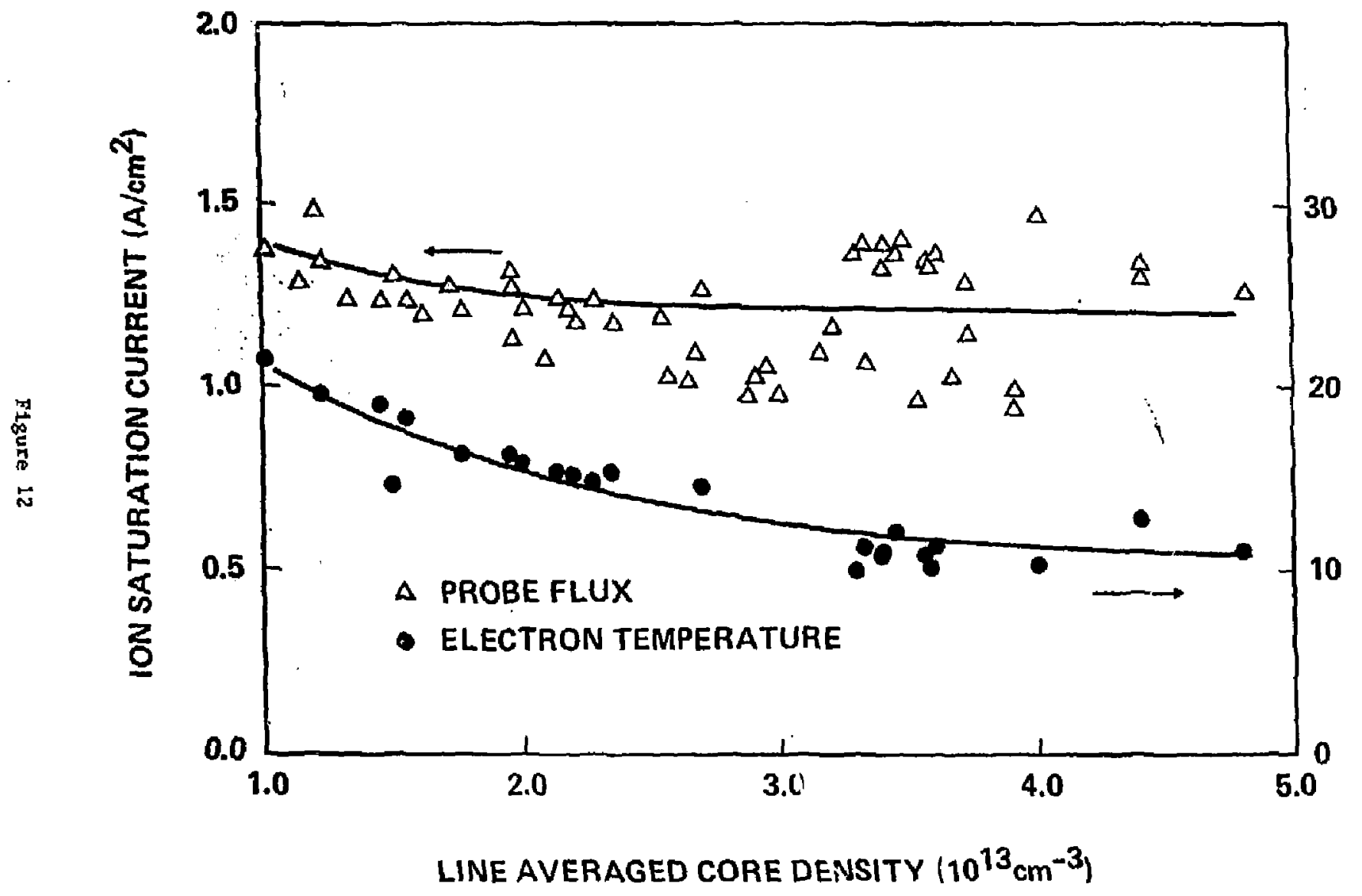

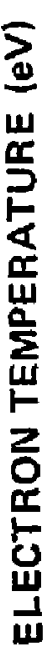




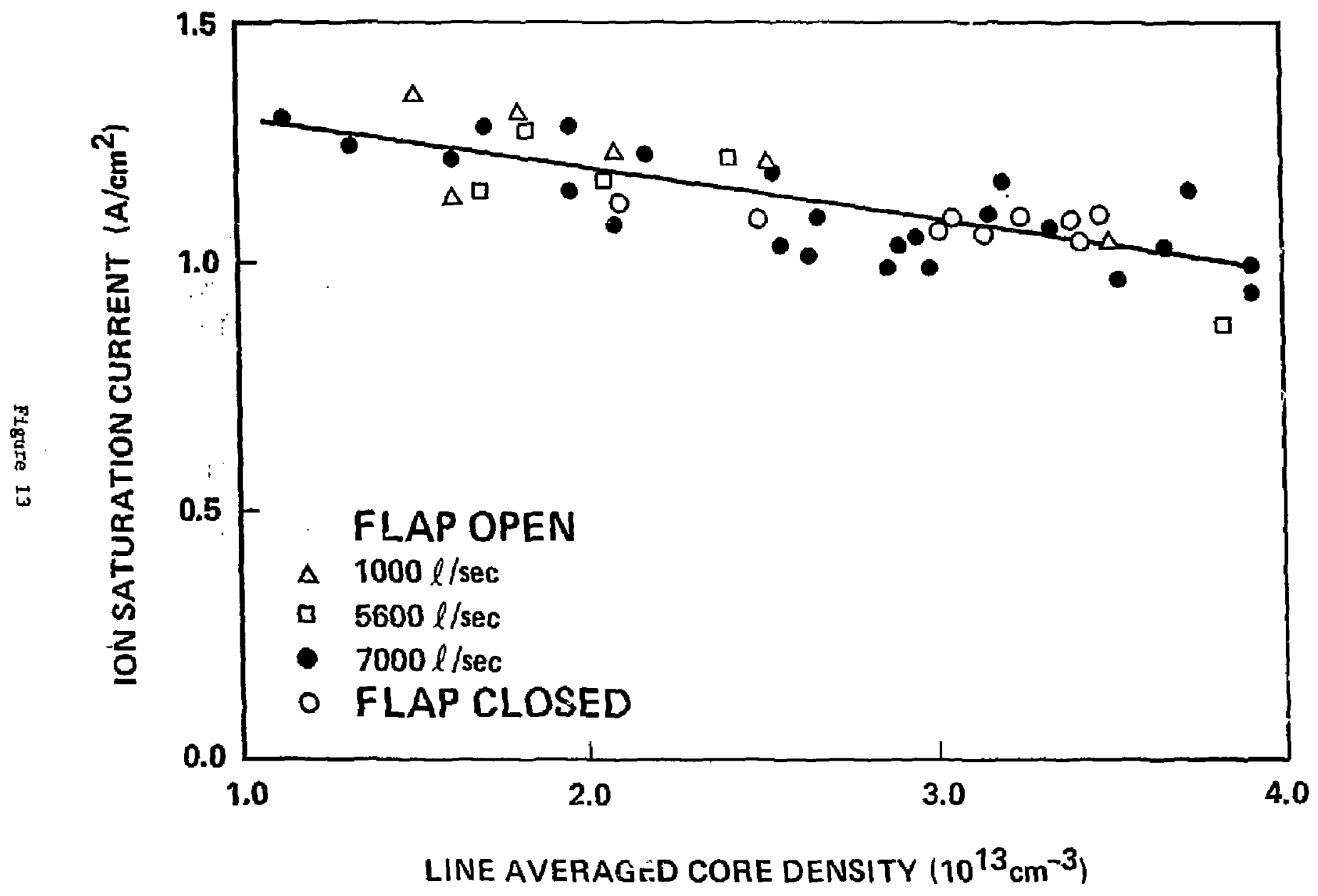




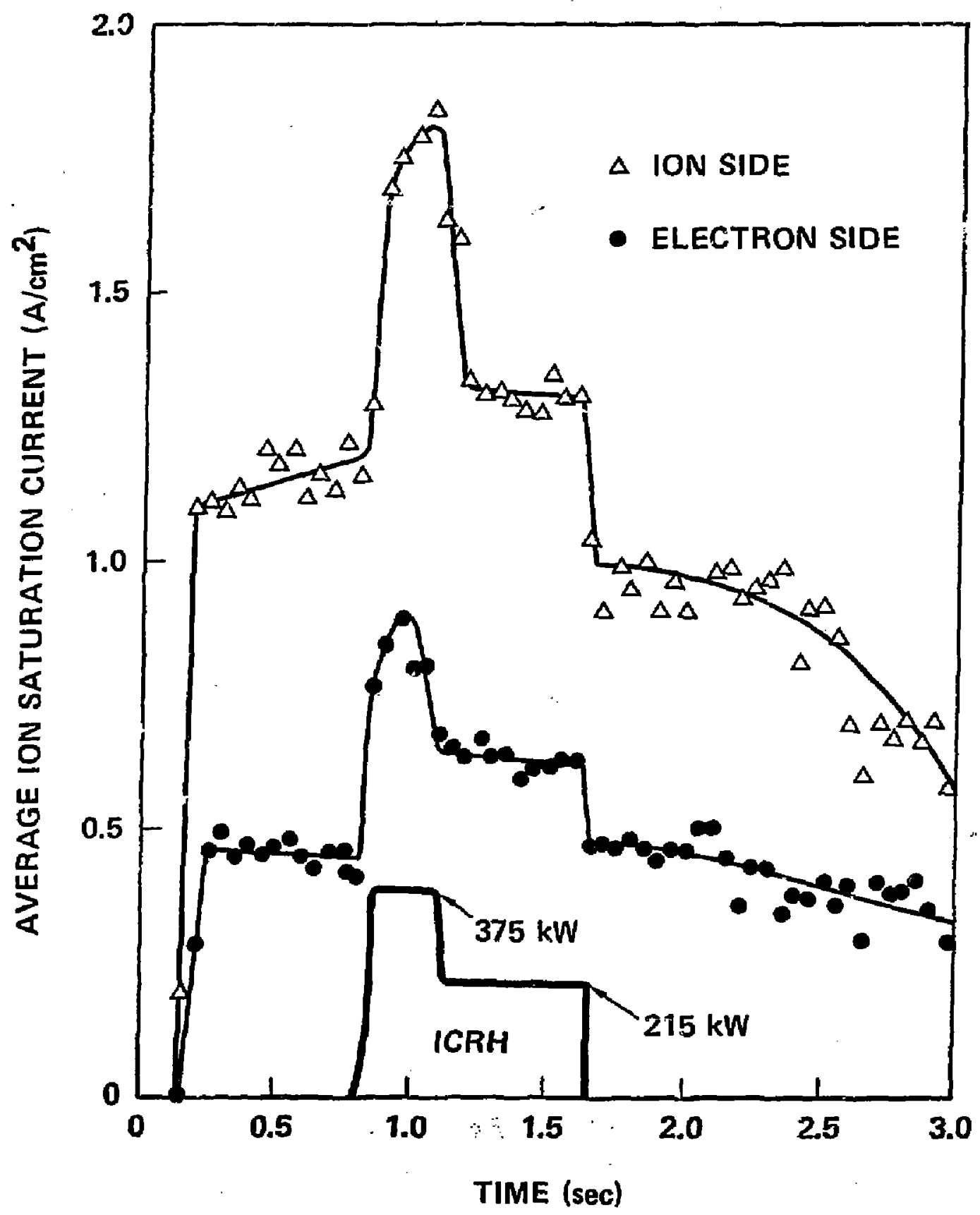

F1gure 14 


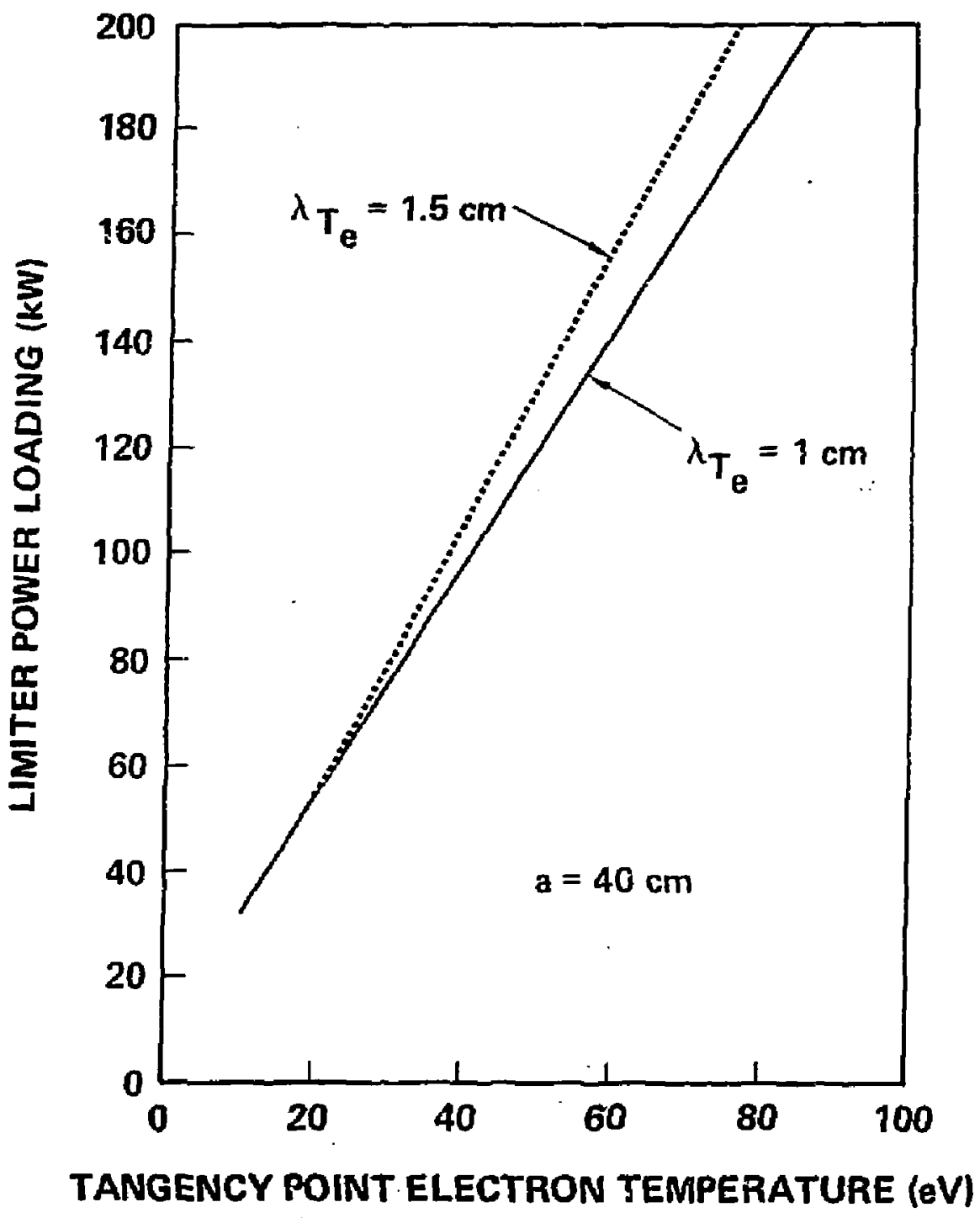

Figure 16 


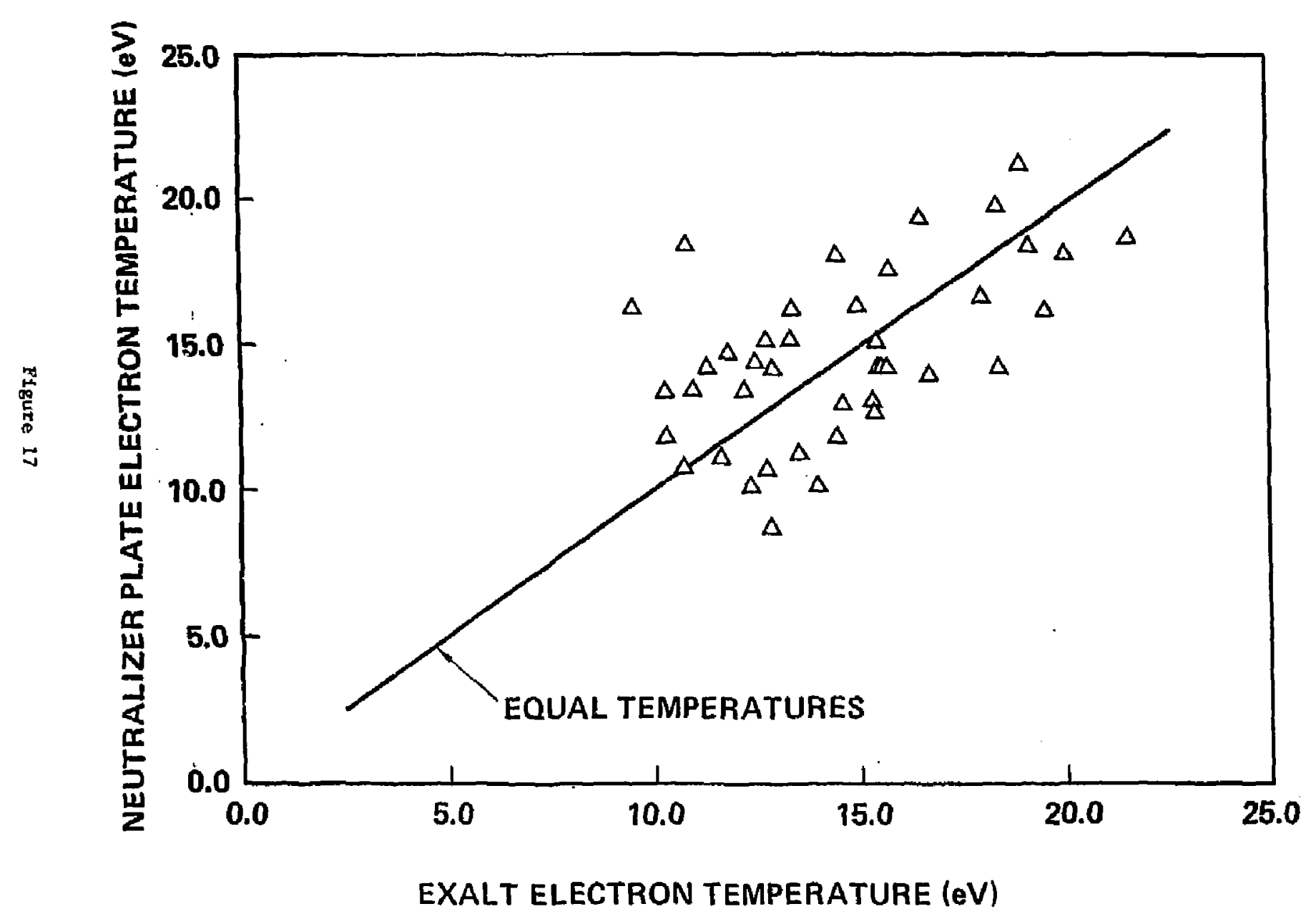

